\section{Research advances in kinase enzymes and inhibitors for cardiovascular disease treatment}

The targeting of protein kinases has great future potential for the design of new drugs against cardiovascular diseases (CVDs). Enormous efforts have been made toward achieving this aim. Unfortunately, kinase inhibitors designed to treat CVDs have suffered from numerous limitations such as poor selectivity, bad permeability and toxicity. So, where are we now in terms of discovering effective kinase targeting drugs to treat CVDs? Various drug design techniques have been approached for this purpose since the discovery of the inhibitory activity of Staurosporine against protein kinase $C$ in 1986. This review aims to provide context for the status of several emerging classes of direct kinase modulators to treat CVDs and discuss challenges that are preventing scientists from finding new kinase drugs to treat heart disease.

Lay abstract: Various protein kinase enzymes are distinctly involved in diverse signal pathways involved in regulating cardiac function in health and disease states. In 1986, the inhibitory activity of Staurosporine against protein kinase $\mathrm{C}$ was revealed, and since then, the interest in finding active kinase inhibitors for use in medicine has grown. Numerous kinase inhibitors have been synthesized in the last two decades, yet none has found its way to the market as a cardiovascular disease treatment; thus, more scientific efforts are needed in this regard.
Rand Shahin*,1, Omar

Shaheen ${ }^{2}$, Faris El-Dahiyat ${ }^{3}$, Maha Habash ${ }^{4}$ \& Sana Saffour ${ }^{5}$

'Department of Pharmaceutical Chemistry, Faculty of Pharmaceutical Sciences, Hashemite University, Az-Zarqa, Jordan

2Department of Pharmacology, Faculty of Medicine, University of Jordan, Amman, Jordan

${ }^{3}$ Department of Clinical Pharmacy \& Pharmacy Practice, Faculty of Pharmaceutical Sciences, Hashemite University, Az-Zarqa, Jordan

${ }^{4}$ Department of Pharmaceutical Sciences \& Pharmacognosy, Faculty of Pharmacy, Aqaba University of Techonology, Aqaba, Jordan

${ }^{5}$ Faculty of Pharmaceutical Sciences, Hashemite University, Az-Zarqa, Jordan *Author for correspondence: Tel.: +962799799044 r.shahin@hu.edu.jo

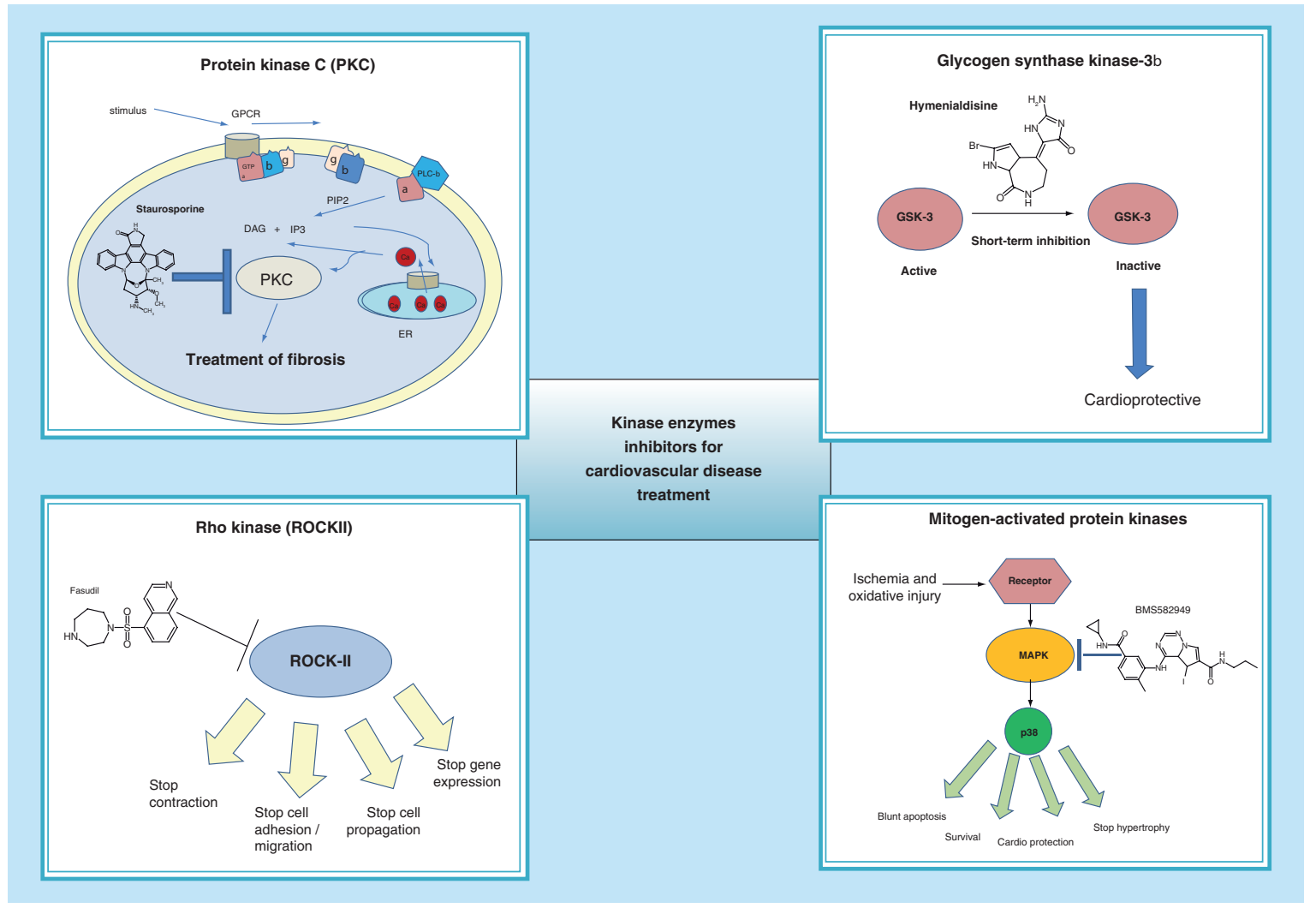


Keywords: CaMK-II $\bullet$ cardiovascular $\bullet$ GSK-3 $\beta \bullet$ inhibitor $\bullet$ kinase inhibitor $\bullet$ MAPK $\bullet$ PKC $\bullet$ protein kinases - ROCK II

\section{First draft submitted: 18 January 2017; Accepted for publication: 29 March 2017; Published online: 8 August 2017}

Nowadays, heart disease is being considered as the leading cause of death among men and women worldwide [1]. According to the CDC, about 610,000 people die of heart disease in the USA annually [2]. Heart disease includes coronary heart disease, heart attack, congestive heart failure and congenital heart disease with coronary heart disease being the most common type; about 375,000 Americans die of heart disease annually $[2,3]$.

Multiple signaling pathways are associated with cardiac function, some of which are beneficial and others injurious [4]. The cardiovascular disease (CVD) state is largely affected by the balance between these signaling pathways, and selective protein kinase inhibitors are being enormously studied as potential new selective therapeutic agents that can substitute traditional receptor blockers for treating CVD [4]. For example, myocardial ischemia is claimed to be caused by the disruption of tightly structured and consistent signal- ing pathways. Recent studies have uncovered three emerging mechanisms of cell death in the ischemic heart [5]: first, the mitochondrial permeability transition and its effector, the mitochondrial permeability transition pore, which is regulated by the PI3K-AKTGSK3 kinase axis; second, the programmed myocardial cell death (necrosis), which is regulated by the interacting protein 1 and 3 kinases. Finally, there is the $\mathrm{Ca}^{2+}$ overload-induced mitochondrial dysfunction, which is regulated by mitochondrial calcium uniporter and $\mathrm{Ca}^{+2}$ calmodulin (CaM)-CaMK-II. Inhibition of each of these kinase pathways has been proposed as a means to limit myocyte death from ischemia/ reperfusion injury [5].

Furthermore, a number of effective small molecule protein kinase inhibitors have been approved by the US FDA; the first was imatinib in 2001 [6]. Afterward, several other inhibitors were subsequently approved. Most of these FDA-approved kinase inhibitors are

\section{Rho kinase (ROCK) \\ Rho kinase is proved to be involved in the development of hypertension, coronary and vascular vasospasm, endothelial dysfunction and atherogenesis.}

\section{Protein kinase C (PKC)}

Aberrant PKC is proved to be linked to various cardiovascular processes such as, vasoconstriction, ischemic preconditioning, and cardiac hypertrophy processes.

\section{Glycogen synthase kinase-3 $\beta$}

Positively induce apoptosis and negatively reduce hypertrophy.

In blood vessels, it promotes angiogenesis.

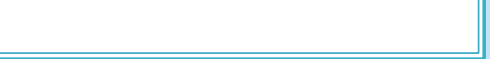

\section{Phosphoinositide 3-kinase}

Class I PI-3Ks have been extensively involved in the cardiovascular system, PI-3K-Akt-GSK-3ß pathway increases cardiac protein synthesis in the cardiac muscle and so causes hypertrophy
Protein phosphorylation reactions related to cardiovascular diseases (CVDs)
Calcium calmodulin kinase $\delta$

(CaMKIII)

CaMKII $\delta$ is proved to regulate cardiac function through phosphorylating various $\mathrm{Ca}^{+2}$ handling proteins in the heart.
Mitogen-activated protein kinases (MAPKs)

One of the major MAPK cascades identified in the myocardium is the stress activated MAPK subfamily; p38 MAPKs. Targeting p38 MAPK signaling pathway is predicted to provide a therapeutic option for treating cardiovascular diseases.

Figure 1. The most impo rtant kinase targets that have been previously reported as kinase targets for heart disease treatment. CVD: Cardiovascular disease. 
indicated for cancer treatment, but recently some other indications have been added to the FDA-approved drug list. For example, tofacitinib, a JAK 3 inhibitor, was approved for treatment of rheumatoid arthritis in 2012 [6]. Unfortunately, until now no kinase inhibitor drug is indicated as a safe and effective therapeutic agent for heart disease, although many pharmaceutical research efforts have been made toward this goal.

Aberrant kinase activity in CVD is due to enhanced stimulation by the activated neurohormonal system [4]. Various kinases are involved in modulating cardiac function via phosphorylation. Figure 1 summarizes the most important kinase targets that have been previously reported as kinase targets for heart disease treatment [6]. The most important are ROCK II [7,8], $\mathrm{Ca}^{+2} \mathrm{CaMK}$ II $\delta$ [9-11], protein kinase C (PKC) [12,13], PI3K [14], GSK-3 $\beta$, FAK and MAPKs [15]. Various kinase inhibitors have been used as research tools to test the putative anticardiac disease activity, but unfortunately none of the lead protein kinase inhibitors has been approved as a therapeutic drug for heart disease treatment up to now.

This review aims toward highlighting the efforts and strategies in literature related to treating heart disease with small molecule protein kinase modulators and providing broad overview of the medicinal chemistry approaches currently used for this aim. In addition, we intend to summarize contemporary (1970-2016) reports of small molecule inhibitors claimed against various CVD-related kinases or reported to carry CVD-related kinases inhibitory activities, and categorize these compounds according to their origin. Furthermore, we intend to discuss the challenges facing the efforts exerted toward finding effective small molecule protein kinase inhibitors and still subduing them from finding new kinase drug inhibitors that can be approved for use in heart disease treatment.

\section{Methods}

In our search, we based our kinase target selection on a review article written by Kumar et al. from the Cardiovascular Research Institute, College of Medicine (TX, USA) in 2007 [4]. Kumar et al. clearly verified $\mathrm{Ca}^{2+}$ CaMK-II, PKC, ROCK, PI3K and MAPK as the most important kinase targets that can attenuate the cardiac function.

After selecting the targets, we made an extensive search to identify published medicinal chemistry studies for each target from 1970 until 2016. Our search strategy involved the use of Boolean connectors for combination of terms such as 'name of the target', 'inhibitor', 'cardiovascular', 'kinase', 'FDA', 'studies', 'pharmaceutical companies', 'clinical studies' and 'drugs'. Equivalent terms were also used whenever pos- sible. The search was limited to full-text articles published in English language from 1970 to 2016. Studies that were written by groups of scientists working in pharmaceutical companies were extensively followed. Electronic database search included PubMed, ISI Web of Knowledge, SciFinder, Science Direct, Springer and Google Scholar. The reference lists in all retrieved article were inspected for additional information. Studies that were connecting the selected targets to disease states other than CVD were excluded.

\section{CaMK-II}

CaMK-IIS is a predominant calcium calcium calmodulin serine/threonine kinase isoform in the heart. Many studies have established its role as an important regulator in cardiac function by phosphorylating various $\mathrm{Ca}^{+2}$ handling proteins in the myocardium such as phospholamban, Ryanodine receptor, L-type $\mathrm{Ca}^{+2}$ channel and other myofilament proteins [16-19]. And so, it is the overactivation of CAMK-II receptor that directly leads to increased cardiac muscle contraction and increased diastolic chamber stiffness, which are important factors in the pathophysiology of a range of cardiac diseases [17].

Myosin light-chain kinase (MLCK) is a family of $\mathrm{Ca}^{+2} / \mathrm{CaM}$-dependent protein kinases that phosphorylate the regulatory MLC (MLC2). MLC posttranslational modification is a key molecular cascade that regulates endothelial permeability and barrier function. MLCK mediated phosphorylation of ATPdependent actomyosin contraction which increases capillary permeability. Similar to smooth muscle, in vascular endothelium, MLC phosphorylation triggers contraction, resulting in endothelial cell membrane retraction, intercellular.

MLC has several isoforms, smooth muscle and nonmuscle MLCK isoforms, respectively; they have wide tissue distribution, and both are expressed in microvascular endothelial cells. Its structure includes actin-binding, catalytic, inhibitory, CaM-binding and kinase-related protein domains, and it also contains a unique fragment containing multiple sites for proteinprotein interaction as well as potential regulatory phosphorylation sites for important kinases such as PKC, protein kinase $\mathrm{A}$ (PKA) and MAPKs' gap formation, and barrier compromise [20].

\section{Natural \& semisynthetic CaMK-II inhibitors}

In our search, we did not find many reports of natural CaMK-II inhibitors; one report by Mayadevi et al. published in 2012 [21] mentioned that curcumin, commonly named as turmeric, which is the principal curcuminoid of turmeric (Curcuma longa, family Zingiberaceae) has an inhibitory action on CaMK-II 


\section{Table 1. Calcium calmodulin serine/threonine kinase II $\delta$ inhibitors in cardiac muscle}

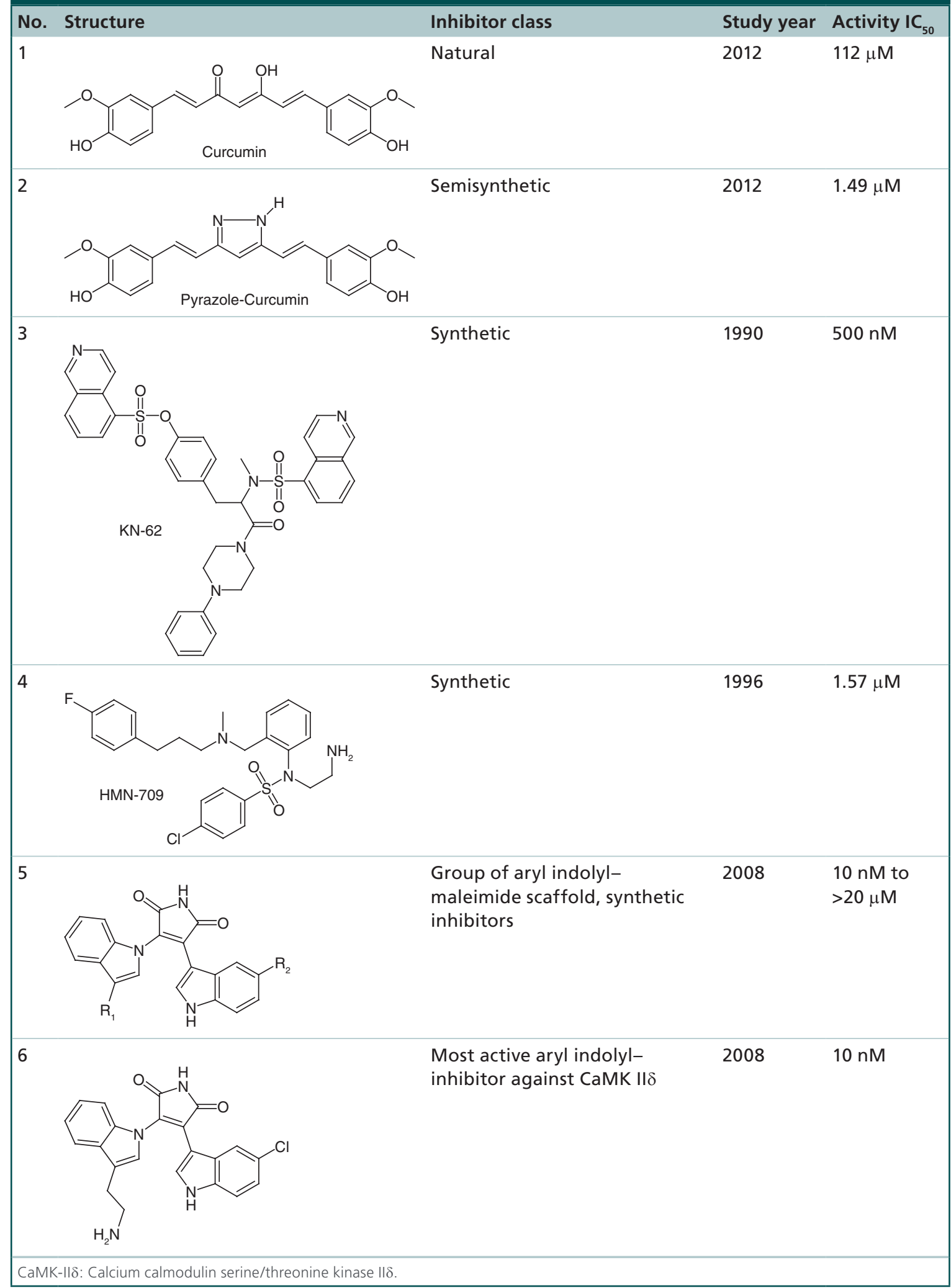




\section{Table 1. Calcium calmodulin serine/threonine kinase II $\delta$ inhibitors in cardiac muscle (cont.).}

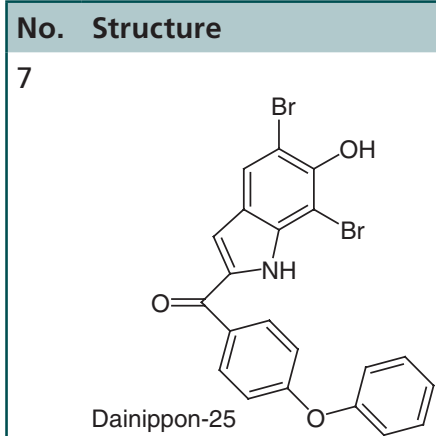

$$
8
$$<smiles>[Y]c1ccnc(Nc2cccc([2H])c2)n1</smiles>
Inhibitor class

Synthetic
Study year Activity IC

2012
Homology modeling synthesis $2008 \quad 0.009-3 \mu \mathrm{M}$ of pyrimidine-based inhibitors

Most active pyrimidine-based $2008 \quad 9 \mathrm{nM}$ inhibitor

Synthetic

2012

$2 \mathrm{nM}$<smiles>CCn1cc(C(N)=O)c(=O)c2cnc(Cc3ccc(N4CCC(N5CCOCC5)CC4)cc3OC)nc21</smiles>

11<smiles>CN1CCCC1CCNc1nc(Nc2ccc(Cl)c(Cl)c2)nc2ccc(Cl)cc12</smiles>

12<smiles>CCN1CCCC(Nc2nc(Nc3cc(Cl)cc(Cl)c3)nc3ccc(Cl)cc23)C1</smiles>

Inhibitor resulted from ligand-

2011

$82 \mathrm{nM}$ based virtual screening CaMK II $\delta$ inhibitor 
(compound 1, Table 1). Also, in this same study, the scientists reported the development of semisynthetic heterocyclic analog of curcumin (3,5-bis[b-(4-hydroxy-3-methoxyphenyl ethenyl]pyrazole), named as pyrazole-curcumin, as a potent inhibitor of CaMK-II $\left(\mathrm{IC}_{50}=1.49 \mu \mathrm{M}\right)$ (compound 2, Table 1) [22].

\section{Synthetic inhibitors of CaMK-II (isoquinoline sulfonamide scaffold)}

CaMK-II was one of the earliest kinase targets studied to treat CVDs. In 1990, a group of Japanese scientists lead by Tokumitsu reported one of the first articles describing the synthesis of CAMK-II inhibitors [23]. It specifically described the synthesis of KN-62 (Table 1), 1-[N,O-bis(5-isoquinolinesulfonyl)$N$-methyl-L-tyrosyl]-4-phenylpiperazine as a specific inhibitor of $\mathrm{Ca}^{2+} / \mathrm{CaMK}$ II [23]

KN-62 (Compound 3, Table 1) was found to inhibit the CaMK-II by interacting with the CaMbinding site on the enzyme [23,24], KN-62 (compound 3, Table 1) inhibits CAMK-II with an $\mathrm{IC}_{50}$ value of $500 \mathrm{nM}[23,24]$ which is tenfold less potent inhibitor for GSK-3 $\beta$ and PKA. Furthermore, KN-62 is reported to inhibit CAMK-I and CAMK-IV at similar concentrations to CAMK-II, which renders it unsuitable to treat specific CVDs. Many synthetic analogs of KN-62 were synthesized and used as standard inhibitors for CaMK-II research studies, and many of its analogs were synthesized.

In 1996, Yokokura et al. reported the synthesis of a nonisoquinoline derivative of $\mathrm{KN}-62$, named as HMN-709 (2-[N-(2-aminoethyl)- $N$-(4-chlorobenzenesulfonyl)] a mino- $N$-(4-fluorocinnamyl) $N$-methylbenzylamine) [25] (compound 4, Table 1), with an $\mathrm{IC}_{50}$ value of $1.57 \mu \mathrm{M}$. HMN-709 was described as a CaM antagonist and classified as an 'ATP noncompetitive' or 'allosteric' compound that binds outside the active site of CAMK [25].

\section{Synthetic inhibitors of CaMK-II (aryl-indolyl maleimide-based scaffold)}

The clear role of CaMK-II $\delta$ in modulating heart function has attracted scientists working in Scios, Inc. (a biopharmaceutical company acquired by Johnson \& Johnson , USA) toward designing and developing potentially active anti-CaMK-II $\delta$ lead inhibitors, among these were Levi et al. [10-11,26]. Levi et al. also synthesized another aryl-indolyl maleimide series of anti-CaMK-IIS compounds with activities ranging from $10 \mathrm{nM}$ to $>20 \mu \mathrm{M}$ (see scaffold 5, Table 1) this effort was based upon manipulating aryl group and the tether joining the basic amine to the indolyl maleimide core of CaMK-II $\delta$ inhibitors (see scaffold 5, Table 1). The most active compound in this series of inhibitors was compound $\mathbf{6}$ in Table 1 with nanomolar activity $\left(\mathrm{IC}_{50}=10 \mathrm{nM}\right)$.

Furthermore, in 2012 Dainippon Sumitomo Pharma $^{\circledR}$ in Osaka, Japan reported the synthesis and of 2-(4-phenoxybenzoyl)-5-hydroxyindole as a novel series of CaMK-II kinase inhibitors. The most potent inhibition of CaMK-II was seen with the dibromo compound Dainippon-25 ( $\mathrm{IC}_{50}=12 \mathrm{nM}$ ) (compound 7, Table 1) [27].

\section{Homology modeling \& synthesis of} pyrimidine-based inhibitors of CaMK-II $\delta$

In 2008, Mavunkel et al. (Scios, Inc.) built a homology model of CaMK-II $\delta$ based on the crystal structure of autoinhibited rat CAMKI (Protein Data Bank code: 1A06) and used the resulted model to synthesize new series of non-ATP competitive pyrimidine based CaMK-II $\delta$ inhibitors [11]. The resulted compounds exhibited an $\mathrm{IC}_{50}$ value ranging from 0.009 to $3 \mu \mathrm{M}$ (see scaffold 8 and compound 9, Table 1).

Later on, in 2012, Beauverger et al. registered a patency for Sanof ${ }^{\circledR}$ (Paris, France) describing the synthesis of 5-oxo-5,8-dihydropyrido[2,3-d] pyrimidine derivatives as CAMK-II kinase inhibitors for treating CVDs [28], Patency No. US 20120277220 A1. The most active compound is Sanofi-32, $\mathrm{IC}_{50}=2 \mathrm{nM}$ (compound 10, Table 1) [28].

\section{Ligand-based drug design of CaMK-II $\delta$ inhibitors}

Virtual screening methodologies are broadly used nowadays to find novel specific kinase inhibitors. Specifically, ligand-based 3D pharmacophores were developed for CaMK-II $\delta$ by Shahin and Taha in 2011 [29]. This study embraced the use of multiple linear regressions and genetic function algorithm in order to build a predictive quantitative structure-activity relationship equation that can describe the activity of potent CaMK-II $\delta$ inhibitors [30]. Finally, this approach resulted in several active inhibitors ranging in their activity from 0.02 to $2.46 \mu \mathrm{M}$ (see compounds 11 and 12, Table 1) [29].

\section{What is in the future for CaMK-II $\delta$ as a target} to treat CVD?

By tracing the development of CAMK-II inhibitors to treat CVD from 1990 till date, we can observe tremendous efforts toward finding new inhibitors for this target. This is due to the well-established scientific certainty about the important role of CaMK-II $\delta$ in the development of heart pathologies [28,31]. Unfortunately, the selectivity has been always an issue in this area. Compounds that target the allosteric binding pocket of CaMK-II are very promising, but still more scien- 
tific effort should be made to reveal the secrets of the allosteric binding site of CAMK-II and to design new inhibitors that can target mutually the hinge region of the ATP-binding pocket and the allosteric site of CAMK-II; this strategy will help in potentiating both the potency and the selectivity of the newly synthesized inhibitors since the sequence homology among the allosteric sites of different kinase inhibitors is quite low, and this provides new opportunities for more specific and minimal off-target inhibition $[32,33]$.

\section{ROCK}

ROCK is a kinase enzyme that belongs to the family of serine/threonine kinase enzymes. ROCK mainly regulates the movement of cells by organizing the actin cytoskeleton, cell adhesion and motility [34]. There are two isoforms of ROCK (ROCK-I and ROCK-II); ROCK-II is preferentially expressed in heart muscle tissue and aberrant ROCK activity has been also linked to various cardiac physiological processes, such as cardiac myocyte hypertrophy, ion channel activity, endothelial permeability and reactive oxygen species production $[4,35]$.

The successful revelation of ROCK's pathophysiological role in heart disease has established its role as a key target for treating CVDs. In addition, the validity of ROCK-II as a target for therapeutic intervention was established by emerging clinical trials [34].

\section{High-throughput screening trials searching for ROCK inhibitors}

A high-throughput screening search campaign aimed toward finding new active Rock inhibitors was conducted by Schroter et al. in 2008 [36]. Throughout this campaign, an institutional library consisting of approximately 600,000 substances was screened for ROCK inhibitors. Finally, this led to the discovery of new pyridine-thiazole-based selective ROCK-II inhibitors, and the most potent was of an $\mathrm{IC}_{50}$ value of $7.2 \mathrm{nM}$ (see compound 13, Table 2) [36,37].

\section{Synthetic ROCK inhibitors}

A wide range of synthetic ROCK inhibitors were synthesized and studied in the last two decades. The first was a low-molecular-weight compound, named as fasudil $\left(\mathrm{K}_{\mathrm{i}}=330 \mathrm{nM}\right)$ against ROCK-II (see compound 14, Table 2) [38]. Fasudil was described in 1997 in a paper published by a Japanese group of scientists, Uehata et al. [39]. fasudil (an isoquinoline derivative) inhibits ROCK via targeting ATP-binding domain in the ROCK kinase, and it has been reported as an effective ROCK inhibitor for treating a wide range of CVDs in clinical studies such as coronary vasospasm, angina, hypertension and heart failure [36,37]. However, it has been reported to have only moderate kinase selectivity [40]. Nevertheless, fasudil was approved in 1995 as a drug for cerebral vasospasm treatment in Japan $(30 \mathrm{mg}$ iv. three-times a day for 14 days) [41,42].

In 2014, ripasudil (a fasudil synthetic derivative, also known as K-115; see compound 15, Table 2) was approved for the treatment of glaucoma in Japan $[40,43-45]$. Presently, fasudil is undergoing clinical trials for the treatment of ischemic heart disease [33].

Chemical optimization of Fasudil also led to another isoquinoline derivatives, for example, compound $\mathrm{H}-1152$ $\left(\mathrm{K}_{\mathrm{i}}=1.6 \mathrm{nM}\right.$; compound 16, Table 2). H-1152 is a compound that exemplifies an excellent investigational tool for ROCK inhibition in vitro $[40,46,47]$ but yet it is not approved for treatment of any medical condition.

The efforts to develop selective analogs of Fasudil continued. In 2012, Lavogina et al. reported the synthesis of conjugates between the 5-isoquinolinesulfonylamide fasudil and the oligo-D-arginine. This compound possesses over 160 -fold selectivity toward ROCK compared with that against PKA [48].

Later on, several other reports revealed the synthesis of new ROCK inhibitors based on other chemical classes; for example, the 4-aminopyridine, indazole, amide and urea series.

The most potent compound of 4-aminopyridine series is $\mathrm{Y}-27632\left(\mathrm{~K}_{\mathrm{i}}=0.14 \mu \mathrm{M}\right.$, compound 17 , Table 2). This compound was presented as an effective potential therapeutic agent to decrease ischemia-reperfusion injury and myocardial fibrosis after myocardial infarction (MI), and in a rat model for chronic hypertension $[4,49]$. The other analogs of 4-aminopyridine ROCK-II inhibitors were synthesized but still inferior in their potencies - for example, compound Y32885 $\left(\mathrm{K}_{\mathrm{i}}=0.2 \mu \mathrm{M}\right)$ [40]. The 4-aminopyridine ROCKII inhibitors were chemically modified to the pyrrolopyridine series and again the selectivity was relatively moderate in these compounds although the potency was modified, for example, compound $\mathrm{Y} 39983\left(\mathrm{IC}_{50} \mathrm{vs}\right.$ ROCK-II is $3.6 \mathrm{nM}$; compound 18 , Table 2) [50].

The well-established validity of ROCK as a target for therapeutic intervention in treating heart diseases and other diseases encouraged the scientist to continue researches on finding new and selective ROCK-II inhibitors. Extensive synthetic studies were conducted in this area; for example, many compounds such as methylenephenyl, benzimidazole, benzothiazole and indazole-substituted pyrazole derivatives were synthesized and studied as ROCK inhibitors.

Indazole-based series of compounds were synthesized by Feng et al. in 2007. Compound SR-1459 (compound 19, Table 2) was the most potent compound in the indazole series at that time and its $\mathrm{IC}_{50}$ versus ROCK-II is $13 \mathrm{nM}$ [51]. 


\section{Table 2. Rho kinase inhibitors.}

\begin{tabular}{|c|c|c|c|c|}
\hline No. & Structure & Inhibitor class & Publication year & Activity \\
\hline 13 & & HTS compound & 2008 & $\mathrm{IC}_{50}=7.2 \mathrm{nM}$ \\
\hline 14 & Fasudil & $\begin{array}{l}\text { Synthetic 'isoquinoline } \\
\text { prototype' }\end{array}$ & 1997 & $\mathrm{~K}_{\mathrm{i}}=330 \mathrm{nM}$ \\
\hline 15 & Ripasaudil & $\begin{array}{l}\text { Fasudil derivative } \\
\text { approved for glaucoma } \\
\text { treatment in Japan }\end{array}$ & 2014 & $\begin{array}{l}\text { ROCK-I }\left(I C_{50}=\right. \\
51 \mathrm{nM}) ; \mathrm{ROCK}-\mathrm{II} \\
\left(\mathrm{IC} \mathrm{C}_{50}=19 \mathrm{nM}\right)\end{array}$ \\
\hline 16 & $\mathrm{H}-1125$ & $\begin{array}{l}\text { Synthetic 'isoquinoline } \\
\text { series' }\end{array}$ & 1997 & $\mathrm{~K}_{\mathrm{i}}=1.6 \mathrm{nM}$ \\
\hline 17 & Y-27632 & $\begin{array}{l}\text { Synthetic } \\
\text { '4-aminopyridine series' }\end{array}$ & 1997 & $K_{\mathrm{i}}=0.14 \mu \mathrm{M}$ \\
\hline 18 & Y39983 & $\begin{array}{l}\text { Synthetic 'pyrrolopyridine } \\
\text { series' }\end{array}$ & 2007 & $\begin{array}{l}\text { ROCK-II }\left(I C_{50}=\right. \\
3.6 \mathrm{nM})\end{array}$ \\
\hline 19 & SR-1459 & Synthetic 'indazole series' & 2006 & $\mathrm{IC}_{50}=13 \mathrm{nM}$ \\
\hline 20 & SR-3677 & $\begin{array}{l}\text { Synthetic benzadioxane- } \\
\text { based compound }\end{array}$ & 2008 & $\begin{array}{l}\text { ROCK-I }\left(I_{50}=\right. \\
56 \mathrm{nM})\end{array}$ \\
\hline
\end{tabular}




\section{Table 2. Rho kinase inhibitors (cont.).}

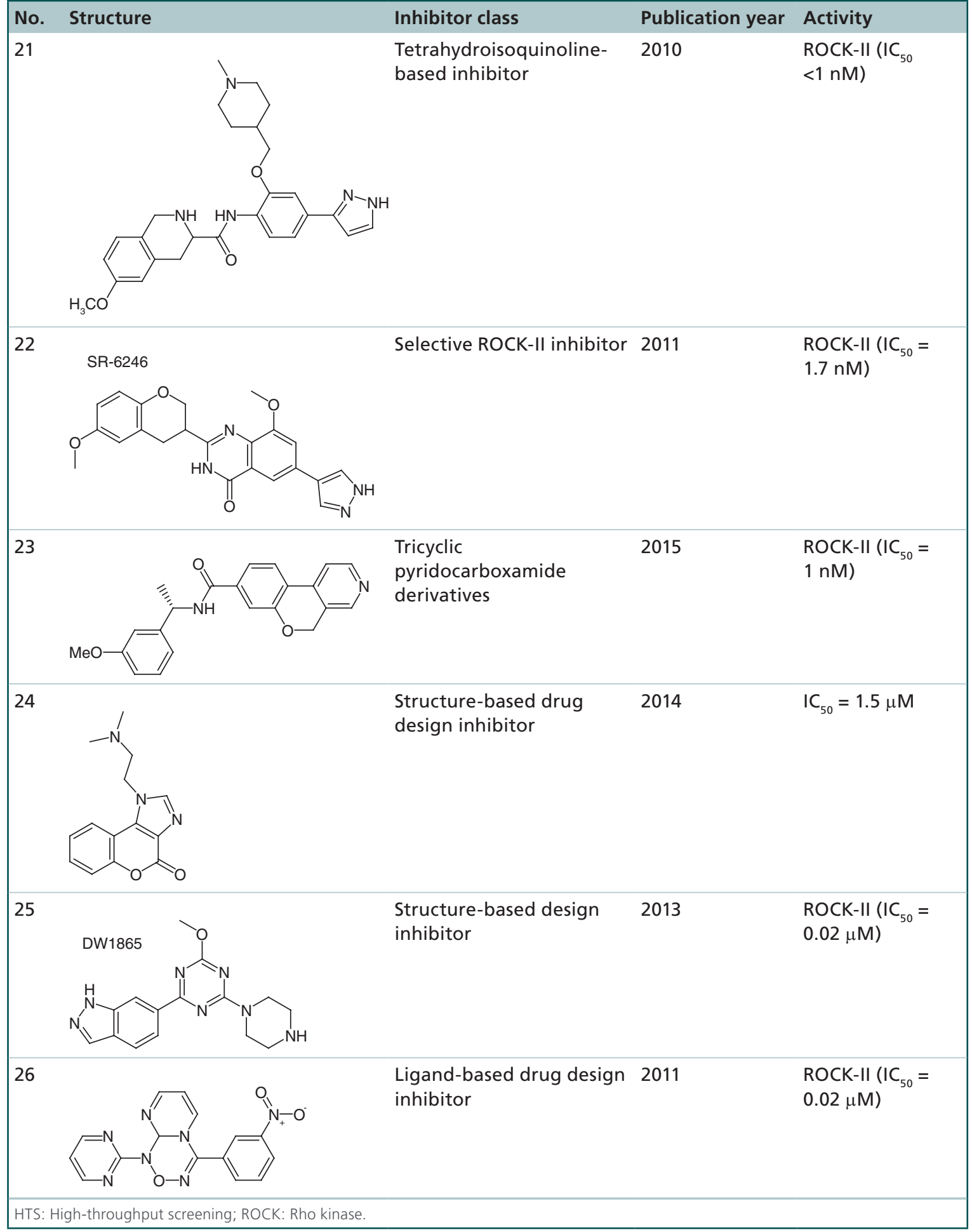

Then in 2008, the same group of scientists presented a new potent benzadioxane-based compound named as SR-3677 (compound 20, Table 2) with an $\mathrm{IC}_{50}$ value of $3 \mathrm{nM}$ against ROCK-II, an $\mathrm{IC}_{50}$ value of $56 \mathrm{nM}$ against ROCK-I and an $\mathrm{IC}_{50}$ value of $3970 \mathrm{nM}$ against PKA, and this was considered a breakthrough toward finding selective inhibitors for ROCK-II enzyme [40,52]. Again, in 2010 Feng et al. reported the synthesis of new tetrahydroisoquinoline derivatives as ROCK inhibitors. These compounds 


\section{Table 3. Protein kinase $\mathrm{C}$ inhibitors.}

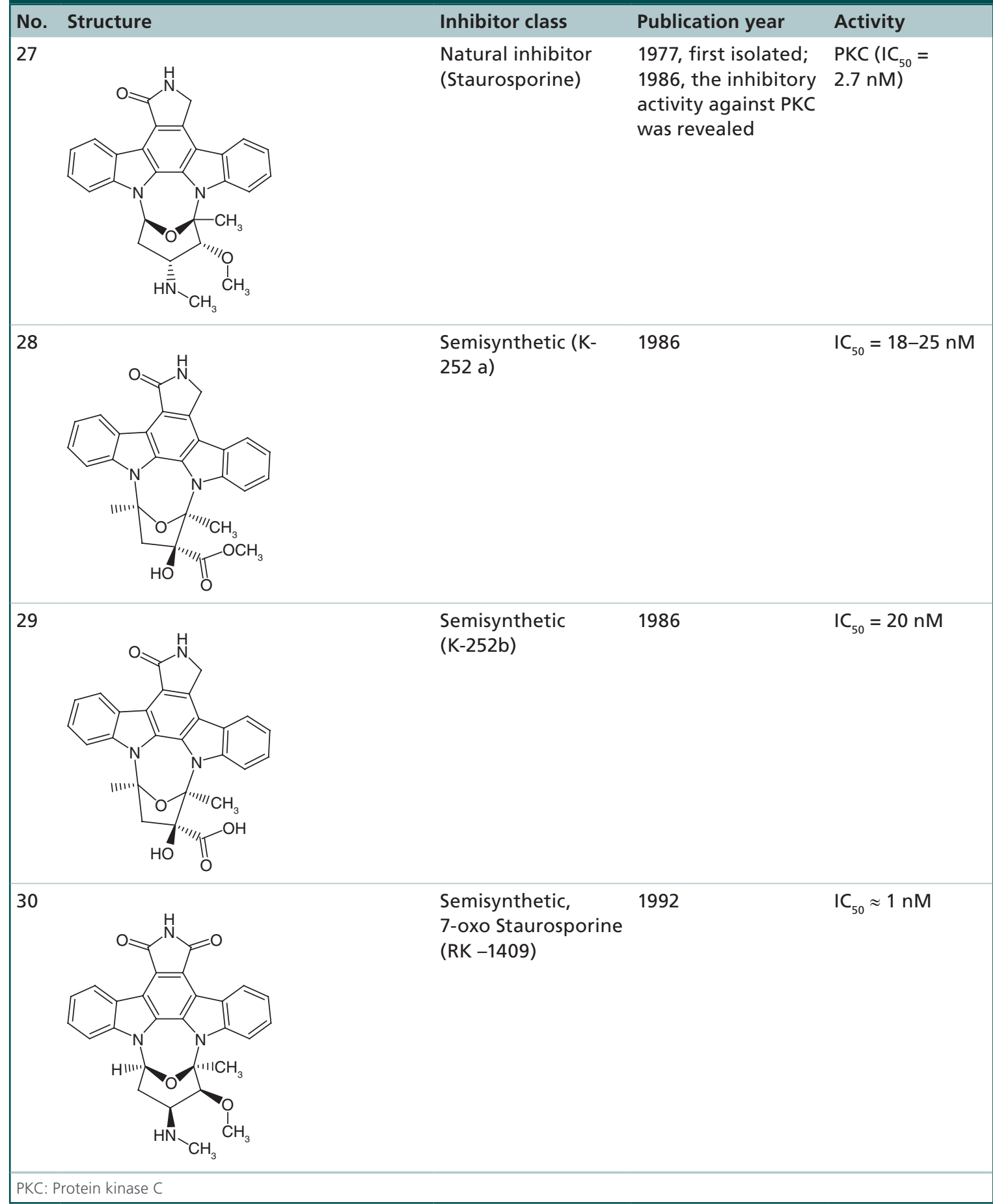

were characterized by their high potency, high selectivity and appropriate pharmacokinetic properties. The most potent compound in this series possessed a nanomolar $\mathrm{IC}_{50}$ value $\left(\mathrm{IC}_{50}<1 \mathrm{nM}\right.$; compound $\mathbf{2 1}$, Table 2) [40,53]. In 2011, Feng et al. modified SR-3677 (compound 20, Table 2) by adding a substituted bulky quinazolinone core; this approach lowered the
PKA inhibition of the newly synthesized compounds and increased their selectivity against ROCK-II enzymes, for example, compound SR-6246 exhibited an $\mathrm{IC}_{50}$ value of $1.7 \mathrm{nM}$ against ROCK-II, an $\mathrm{IC}_{50}$ value of $6.7 \mathrm{nM}$ against ROCK-I and an $\mathrm{IC}_{50}$ value of more than $14 \mu \mathrm{M}$ against PKA (see compound 22, Table 2) [40]. 


\section{Table 3. Protein kinase C inhibitors (cont.).}

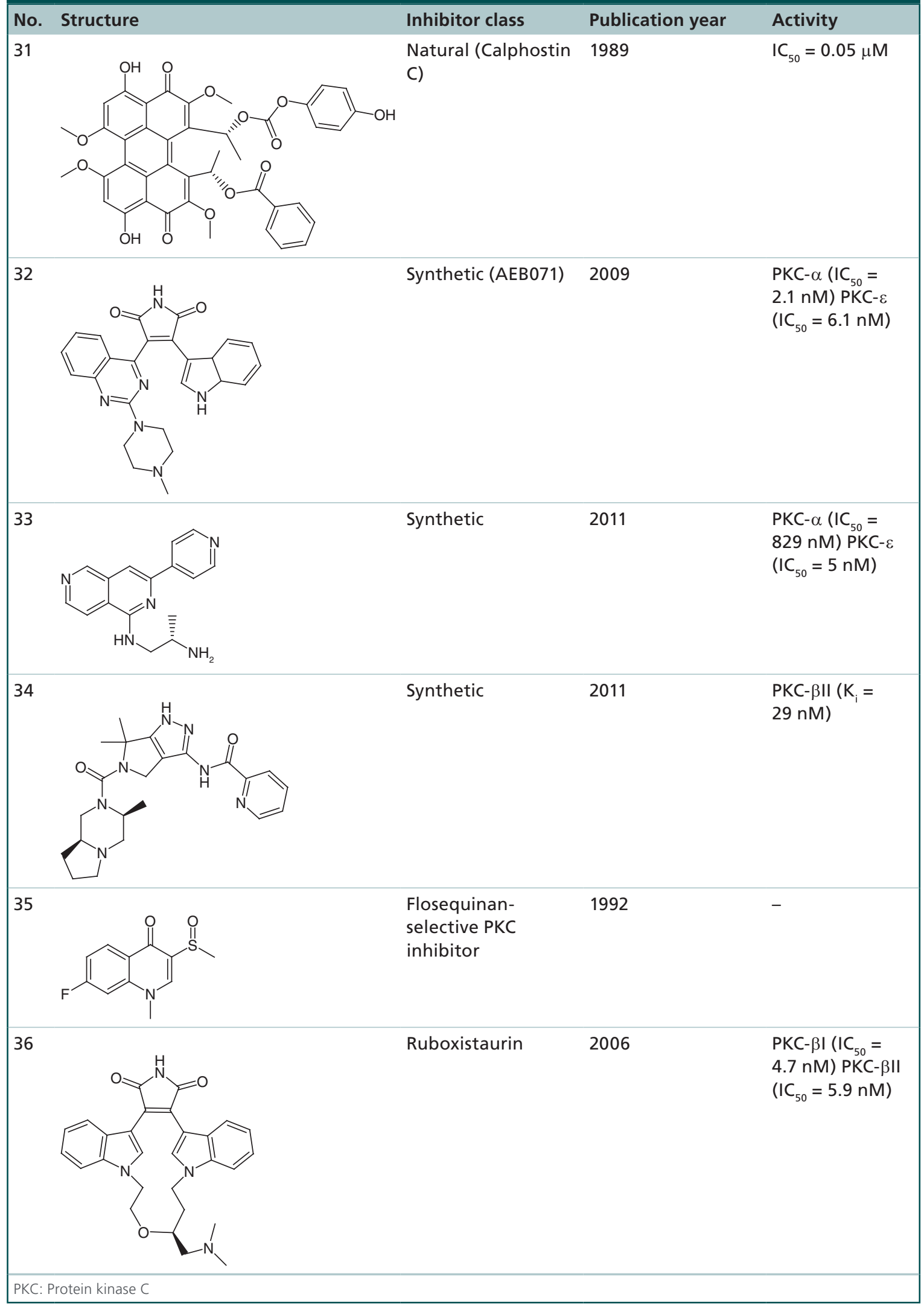




\section{Table 4. MAPK inhibitors.}

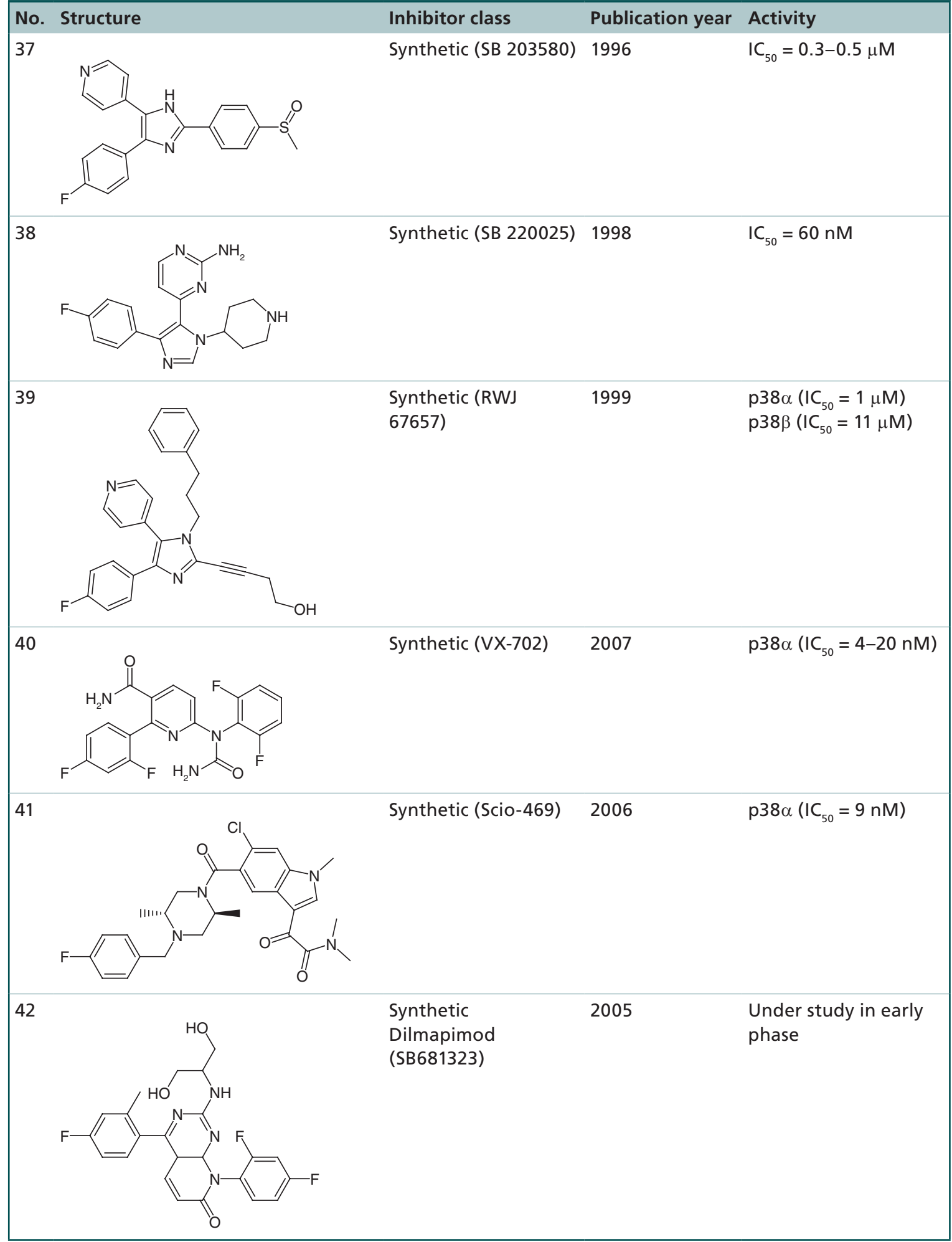

In 2015, Bristol-Myers Squibb (BMS; NY, USA) registered a patency for tricyclic pyridocarboxamide derivatives as inhibitors against the ROCK enzyme, and the most potent compound in this patency exhibited an $\mathrm{IC}_{50}$ value of $<1 \mathrm{nM}$ for ROCK-II (see compound 23, Table 2) [54]. 


\section{Table 4. MAPK inhibitors (cont.).}

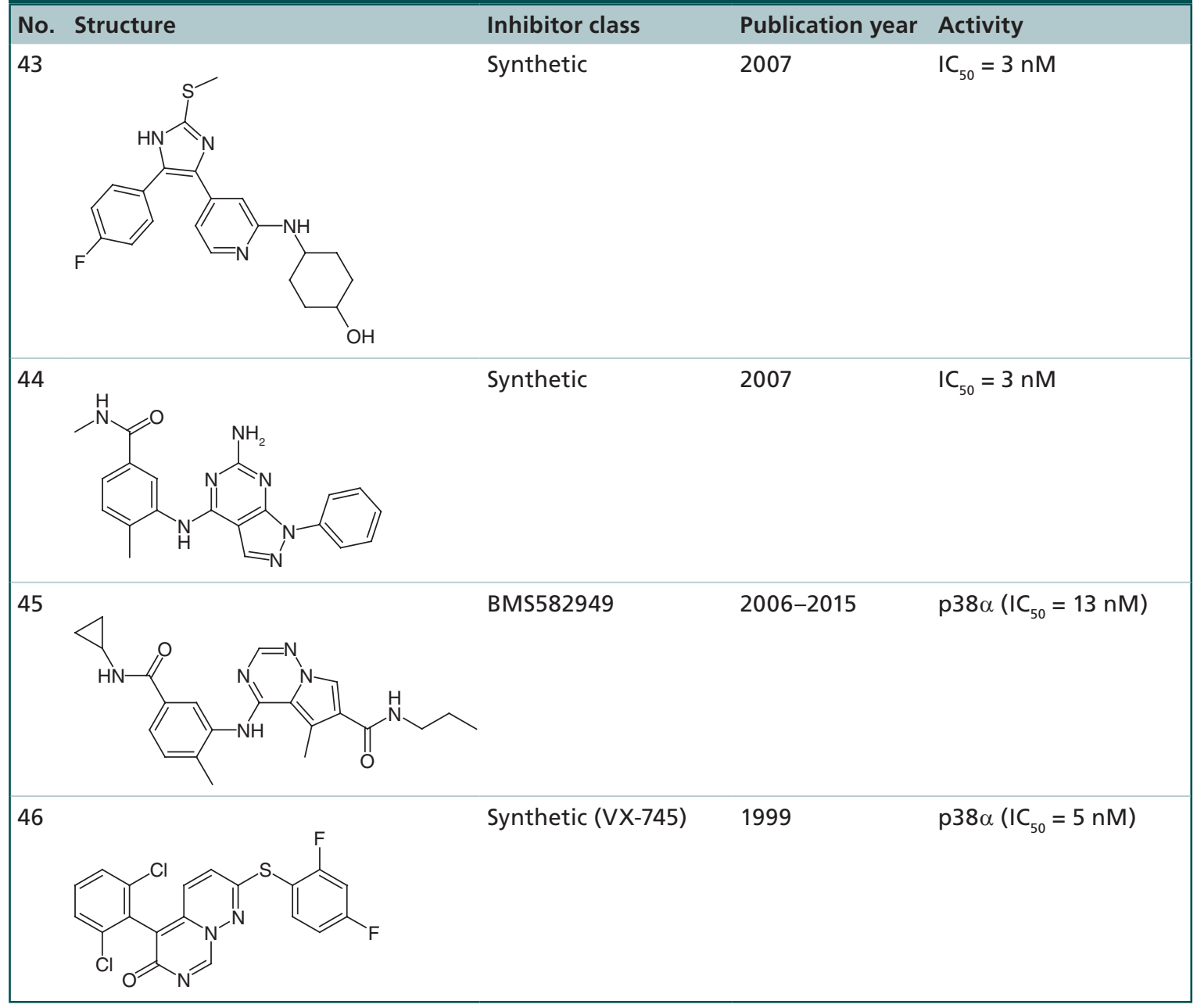

\section{Structure-based drug design of ROCK-II} inhibitors

A structure-based study of ROCK inhibitors was first published in 2010 by Mishra et al. [55]. This study was based on a structure-guided design of eight co-crystal structures of ROCK-inhibitor complexes. Then, the energy-based pharmacophores resulted from this study were used as filters to virtually screen the commercially available Asinex database containing 525,807 molecules. This study resulted in identifying new ROCK inhibitors. The most potent compound in this study showed an $\mathrm{IC}_{50}$ value of $1.5 \mu \mathrm{M}$ against ROCK kinase (compound 24, Table 2). The low micromolar activity of the most active resulted compound in this study prompted the authors to mention that the identified lead may constitute a prototypical molecule for further optimization as an anti-ROCK inhibitor [55].

In 2013, a group of Korean scientists reported the discovery of new potent ROCK inhibitor named as DW1865 (compound 25, Table 2, $\mathrm{IC}_{50}$ against
ROCK-II $=0.02 \mu \mathrm{M}$ ) [56] by applying rational virtual discovery strategies including structure-based drug design and straight structure-activity relationship. DW1865 was described to be ten-times more potent in inhibiting ROCK activity than Fasudil. In addition, the activity of DW1865 was shown to be highly selective for ROCK-II compared with 13 other kinases. DW1865 was described to cause vasorelaxation in phenylephrine- or 5-hydroxytriptamine-induced contraction in a concentration-dependent manner and to exert a significant and dose-related reduction in blood pressure in spontaneously hypertensive rats [56].

\section{Ligand-based drug design of ROCK-II}

Ligand-based 3D pharmacophores were developed for ROCK by Shahin and Taha in 2011 [57]. This work included multiple linear regressions and genetic function algorithm processes in which several $2 \mathrm{D}$ and $3 \mathrm{D}$ descriptors were allowed to compete for building a predictive quantitative structure-activity relationship 
Table 5. Inhibitors of glycogen synthase kinase-3 $\beta$.

$\begin{array}{lll}\text { Natural (hymenialdisine) } & 2000 & \\ \mathrm{IC}_{50}=0.01 \mu \mathrm{M}\end{array}$

model. Eight submicromolar ROCK-II inhibitors were identified. The most potent ones have $\mathrm{IC}_{50}$ values of 0.7 and $1.0 \mu \mathrm{M}$ [57] (most active is compound 26, Table 2).

\section{Current status of ROCK-II as cardiovascular treatment target}

As we have described earlier, extensive studies were applied by several research groups to identify novel, potent and selective inhibitors against ROCK-II; from our point of view, these studies were not targeted against ROCK-II as the key role player in the pathogenesis of heart disease. Instead, these studies empha- sized on ROCK-II as a target to treat several other diseases such as cerebral vasospasm, glaucoma, diabetic retinopathy, kidney disease and even psoriasis [58,59]. Although there were major advances in finding ROCK inhibitors to treat these diseases, for example, compound Ar-13324 (structure not disclosed) developed by Aries $^{\circledR}$ has reached Phase II in clinical studies to treat glaucoma [58,59] but yet no ROCK inhibitors were registered to treat any CVD $[58,59]$.

Based on the fact that many ROCK-II inhibitors were identified to be potent and selective in addition to the fact that the role of ROCK-II in the pathogenesis of 
heart disease is very well established, we suggest that the next step should emphasize on bridging the gap between the previously synthesized ROCK-II inhibitors and their efficacy in treating hypertensive and heart-related conditions in animal models and clinical studies.

\section{Protein kinase C}

PKC enzymes are group serine/threonine kinases that are expressed in many tissues inside the human body, including the myocardium tissue [60]. It has been recently cited that some of PKC isozymes are implicated in the propagation of different types of heart diseases; for example, PKC- $\alpha$ activation was correlated with decreased cardiac contractility and uncoupling of $\beta$-adrenergic receptors [61-63]. Also, PKC- $\beta$ II was shown to be involved in dysregulation of calcium handling in myocardium tissue $[64,65]$. In addition to that, activation of PKC- $\varepsilon$ in heart muscles was accompanied with increased fibrosis, fibroblast proliferation and inflammation which may finally lead to heart failure [66].

\section{Natural inhibitors of PKC}

The indolocarbazole alkaloid staurosporine was first isolated by Omura et al. from Streptomyces staurosporeus in 1977 [67]. Later on in 1986, the inhibitory activity of Staurosporine against PKC was revealed $\left(\mathrm{IC}_{50}=2.7\right.$ nM) [67,68]. This discovery opened the door widely toward new drug discovery trials targeting kinases in general. Staurosporine (compound 27, Table 3) was first named as AM-2282; later on, many of its analogs were synthesized. Another series of PKC inhibitors was isolated from the culture of Nocardiopsis species; among them are $\mathrm{K}-252 \mathrm{a}\left(\mathrm{IC}_{50}=18-25 \mathrm{nM}\right.$; compound 28, Table 3), K-252b ( $\mathrm{IC}_{50}=20 \mathrm{nM}$; compound 29, Table 3) and $\mathrm{K}-252 \mathrm{c}\left(\mathrm{IC}_{50}=2.45 \mu \mathrm{M}\right)$ [68-70]. Furthermore, in 1992, RK-1409 (7-oxo Staurosporine; compound 30, Table 3) was isolated from Streptomyces platensis, subsp. Malvinus and showed significant PKC inhibitory activity $\left(\mathrm{IC}_{50} \approx 1 \mathrm{nM}\right)[68-70]$. Several other Staurosporine derivatives were reported to be isolated and reported in the literature but all with submicromolar PKC inhibitory concentrations [68-70].

Furthermore, Other PKC natural inhibitors named as calphostins $\mathrm{A}-\mathrm{E}$ were reported in the literature. These compounds were isolated from the fungus Cladosporium cladosporioides $\left(\mathrm{IC}_{50}\right.$ ranging from 0.05 to $6.36 \mu \mathrm{M})$ with Calphostin C (UCN-1028C) showing the highest potency among them (compound 31, Table 3) [71].

\section{Synthetic inhibitors of PKC}

In 2009, Wagner et al. synthesized new maleimidebased series of compounds and evaluated them against different types of PKC isotypes [72]. In this study, compound AEB071 (compound 32, Table 3) was the most potent with activities against PKC- $\alpha\left(\mathrm{IC}_{50}=\right.$ $2.1 \mathrm{nM})$, PKC- $\varepsilon\left(\mathrm{IC}_{50}=6.1 \mathrm{nM}\right)$ [72]. Later, in 2011 Van Eis et al. reported the synthesis of new 2,6-naphthyridine derivatives as PKC inhibitors; compound $\mathbf{1 1}$ in the reported paper (compound 33, Table 3) was the most potent PKC- $\alpha\left(\mathrm{IC}_{50}=829 \mathrm{nM}\right)$, PKC- $\varepsilon\left(\mathrm{IC}_{50}\right.$ $=5 \mathrm{nM}$ ) [73]. Another study was published in 2011 by $\mathrm{Li}$ et al. which identified novel pyrrolopyrazoles series of PKC- $\beta$ II inhibitors [74]; compound $\mathbf{2 3}$ in the reported paper showed superior results $\left(K_{i}=29 \mathrm{nM}\right)$ against PKC- $\beta$ II (see compound 34, Table 3).

\section{Clinical cardiovascular trials related to PKC inhibition}

The drug flosequinan (see compound 35, Table 3) is a nonselective PKC inhibitor that was indicated for treatment of congestive heart failure. It was sold under the name Manoplax ${ }^{\circledR}$ and then was withdrawn from the US market in October 1993 due to increased hospitalization and mortality [75,76]. Also, ruboxistaurin (LY333531; see compound 36, Table 3) is a selective inhibitor of different PKC isoforms; PKC- $\beta 1$ and PKC$\beta 2\left(\mathrm{IC}_{50}=4.7\right.$ and $5.9 \mathrm{nM}$, respectively) [75,76]. More-

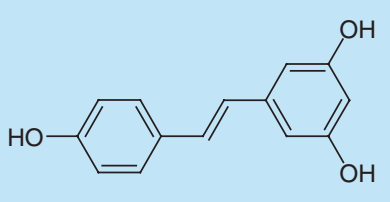

52

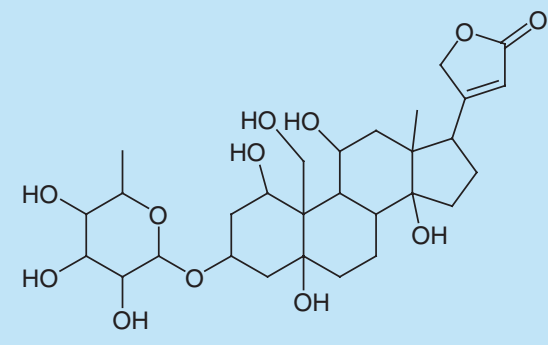

53

Figure 2. Five PI3K/AKT/eNOS activators. Compound 52: resveratrol; compound 53: the cardiac glycosides (ouabain). 
over, the $\mathrm{IC}_{50}$ values for PKC isoforms $\alpha, \gamma, \delta, \varepsilon, \zeta$ and $\eta$ are $360,300,250,600,>100,000$ and $52 \mathrm{nM}$, respectively [75,76]. Ruboxistaurin (LY333531) was introduced by Elli lilly as an investigational drug for treatment of diabetic peripheral neuropathy and retinopathy. Unfortunately, no progress was informed for this proposal. On May 2006, Elli lilly filed with Europe, the Middle East and Africa. Its current development status in the Europe is unclear at this stage, but still investigational clinical studies for this indication are ongoing [75]. Finally, on 15 March 2007, Eli Lilly withdrew its marketing authorization application for ruboxistaurin for diabetic retinopathy and from the FDA [77].

PKC as a future cardiovascular treatment target The exact role of different isoforms of PKC in cardiac disease is still ambiguous; taking into consideration that the PKC family of enzymes includes three classes and 12 isoforms, and that $\mathrm{PKC}$ isoforms have four structurally conserved domains (C1-C4) and five variable domains (V1-V5) [78] accordingly we can say that the selectivity of the PKC targeting drugs is an issue that can cause unacceptable on-target and off-target effects [79]. The future PKC targeting drugs should be more focused on monitoring the pharmacodynamics of new PKC modulators and revealing more information about the biology of various PKC isoforms.

\section{p38 MAPK}

MAPKs include many serine-threonine kinases; one of the major MAPK cascades identified in the myocardium is the stress-activated MAPK subfamily; p38 MAPKs [80]. Targeting p38 MAPK signaling pathway is established to provide a therapeutic option for treating CVDs [80,81]. For example, it has been proven that myocardium p38 MAPK was evidently activated throughout the development of cardiac hypertrophy disease and inactivated during decompensation stages [80,82]. In addition, p38 MAPK inhibition has been demonstrated to blunt apoptosis in vivo and ex vivo cardiac ischemia/reperfusion injury models [83]. Also, cardio protection is also observed in a transgenic heart expressing a dominant negative mutant of p38 $\alpha$ MAPK [83]. All of these studies and many others encouraged the scientists in pharmaceutical companies to search for new p38 MAPK active hits.

\section{Natural inhibitors of p38 MAPKs}

Naturally occurring polyphenols are antioxidants that are able to attenuate MAPK-induced signaling pathways, and so phenolic compounds are able to decrease inflammatory reactions, platelet aggregation processes, atherosclerosis and hypertension thus protecting the cardiac muscles [84].
Phenolic compounds cover a wide range of natural compounds; the most important group is the flavonoids such as epigallocatechin gallate (found in tea). Epigallocatechin gallate has been found to attenuate angiotensin-II and pressure overload mediated cardiac hypertrophy $[80,84]$. Quercetin is also a flavonoid polyphenol, and it is also found to abolish hydrogen peroxide-induced endothelial cell apoptosis via blocking the phosphorylation of p38 MAPK [80].

Moreover, resveratrol is a type of natural phenol found in grapes, blueberries, raspberries and mulberries, and is also proposed to treat ischemic heart disease via attenuating MAPK/SAPK/cAMP response element-binding protein [80].

Furthermore, all of the previously mentioned natural inhibitors of p38 MAPKs were based on preclinical researches and yet no actual natural inhibitor of p38 MAPKs is considered as a real drug to treat stress related-cardiac hypertrophy or any cardiac condition.

\section{Synthetic inhibitors of p38 MAPKs}

One of the first synthesized compounds against p38 MAPKs is the SmithKline Beecham compound SB 203580 (compound 37, Table 4) [85]. SB 203580 was first synthesized in 1996 and reported to inhibit p38 MAPK, nitric oxide production and inducible nitric oxide synthase in bovine cartilage-derived chondrocytes; nowadays it is considered as the literature standard for p38 kinase inhibitor $\left(\mathrm{IC}_{50}=0.3-0.5 \mu \mathrm{M}\right)$ [86].

Moreover, in 1998 SmithKline Beecham synthesized compound SB 220025 (compound 38, Table 4), which is also a specific inhibitor of human p38 MAPK with an $\mathrm{IC}_{50}$ value of $60 \mathrm{nM}$ [86].

In 1999, Johnson Pharmaceutical Research Institute reported the synthesis of RWJ 67657 (compound 39, Table 4) which is selective p38 $\alpha$ and $p 38 \beta$ inhibitor $\left(\mathrm{IC}_{50}=1\right.$ and $11 \mu \mathrm{M}$, respectively). RWJ 67657 displayed no activity at $\mathrm{p} 38 \gamma$ and $\mathrm{p} 38 \delta$, and was reported to exhibit cardio protective and anti-inflammatory activity in addition to being orally active [87]. RWJ 67657 is approximately tenfold more potent than the literature standard of p38 kinase inhibitor SB 203580 (compound 37, Table 4) in all p38-dependent in vitro systems tested [87].

Again, scientists were interested in p38 MAPK as a target to treat chronic inflammatory diseases such as rheumatoid arthritis. Nevertheless, some synthesized p38 MAPK inhibitors were indicated to treat congestive heart failure such as VX-702 (compound 40, Table 4), Scio-469 (compound 41, Table 4) and Dilmapimod (SB681323; GlaxoSmithKline) (compound 42, Table 4). Dilmapimod (SB681323) is still under study in early phase (Phase IIa) as a treatment for acute lung injury and acute respiratory distress 
syndrome to evaluate its safety and tolerability, as a potent, selective inhibitor of p38 $\alpha$ (MAPK) [88]. Unfortunately, SB681323 is not filed to treat stressrelated congestive heart failure though it was one of its proposed indications in the early drug design stages [88].

In the following years, many groups of scientists continued the search for new inhibitors to p38 MAPK; for example, a German group led by Laufer et al. from the Institute of Pharmacy, Eberhard-Karls-University reported the synthesis of novel tri- and tetrasubstituted imidazole analogs as inhibitors of p38 MAPK [89], with most active compound 43, Table 4 $\left(\mathrm{IC}_{50}=3 \mathrm{nM}\right)$. Simultaneously, a group of scientists from the USA led by Das from BMS reported the synthesis pyrazolopyrimidine-based series of compounds as a novel scaffold for selective p38a inhibitors. In this study, the most active compound was compound 44 (Table 4; $\mathrm{IC}_{50}=3 \mathrm{nM}$ ) [89, 90]. In 2015, BMS filed compound BMS582949 (see compound 45, Table 4) for Phase II clinical trial as a treatment for atherosclerosis [91]. Unfortunately, the finding of the study revealed that treatment with BMS582949 did not reduce arterial inflammation relative to placebo compared with statins [91], but compound BMS582949 is still under study to treat moderate-to-severe plaque psoriasis [92].

The efforts are going on to synthesize new p38 MAPK inhibitors to treat cardiac myopathies but, as we mentioned, other than compound BMS582949, no compound has been filed to the FDA for this purpose. Hopefully later on, research data will reveal more about p38 inhibitors that have therapeutic use beyond their well-known anti-inflammatory properties as stress-related cardiac hypertrophy drugs [80].

\section{MAPK as a cardiovascular treatment target}

Noticeably, no active p38 MAPK inhibitor for treating stress-related cardiac hypertrophy has reached the market. Yet, some p38 MAPK inhibitors such as Vertex 745 (VX-745) (compound 46, Table 4) and SCIO-469 (compound 41, Table 4) are considered as pharmacological p38 MAPK inhibitors that are under development for treating rheumatoid arthritis [93-95]. In the previous discussion, we discussed about some of the efforts to find new p38 MAPK inhibitors to treat stress-related cardiac hypertrophy. We can see that the pharmaceutical companies are interested in finding MAPK inhibitors to treat the inflammatory condition associated with the atherosclerosis pathogenesis, but no MAPK inhibitor has proved to be superior over statins in this regard. As for $\mathrm{p} 38$ MAPK, it is crystal clear that we are a few steps away from finding a new kinase inhibitor to treat CVD hopefully in the near future; we will see such a drug in the market.

\section{GSK-3 $\beta$}

In myocardium, GSK-3 $\beta$ positively regulates apoptosis and negatively regulates hypertrophy $[4,96]$. Inhibition of GSK-3 $\beta$ has been proposed as an approach to improve postischemic cardiac myocyte survival and enhance cardioprotection $[4,97]$. In addition to that, it was found that short-term inhibition of GSK may be cardioprotective; however, long-term or sustained inhibition of GSK-3 $\beta$ may contribute to the development of hypertrophy.

\section{Natural inhibitors of GSK-3 $\beta$}

In a screening study that was conducted and published by Meijer $e t a l$. in year 2000, the marine sponge constituent hymenialdisine (compound 47, Table 5) was found to be a potent inhibitor of GSK-3 $\beta$ ( $\mathrm{IC}_{50}$ $=0.01 \mu \mathrm{M})$ [98]. In 2001, another study conducted by Leclerc et al. revealed the discovery of indirubin as a new natural inhibitor of GSK-3 $\beta$ [99]. Indirubin was extracted from Danggui Longhui Wan, a traditional Chinese medicine, and was found to potently inhibit GSK-3 $\beta\left(\mathrm{IC}_{50}=0.009 \mathrm{nM}\right.$; compound 48, Table 5) [99].

\section{Synthetic inhibitors of GSK-3 $\beta$}

In 2000, Leost et al. reported that paullones, a family of synthetic benzazepinones, act as potent inhibitors of GSK-3 $\beta\left(\mathrm{IC}_{50}: 4-80 \mu \mathrm{M}\right)$ [100]. Table 4 shows the structure of alesterpaullone (compound $49 ; \mathrm{IC}_{50}$ : $4 \mu \mathrm{M})[100]$.

In 2002, a group of scientists (Metty et al.) [101] performed a selectivity study on 26 kinases. This study showed that the synthetic compound aloisine A (compound 50, Table 5) is highly selective for GSK-3 $\beta\left(\mathrm{IC}_{50}=0.65 \mu \mathrm{M}\right)$, but still GSK-3 $\beta$ was evaluated against cancers and neurodegenerative disorders such as Alzheimer's disease but not for heart disease treatment [101]. Later on in 2003, Zhang et al. synthesized a novel series of macrocyclic bisindolyl maleimides containing linkers with multiple heteroatoms and evaluated against GSK-3 $\beta$ (compound 51, Table 5) [102].

Obviously, the efforts that have been made to find active inhibitors by the pharmaceutical companies against GSK-3 $\beta$ are much less than those made to find inhibitors against other previously mentioned targets. This might be due to the fact that we still need extra studies and researches to establish the role of GSK-3 $\beta$ as a useful therapeutic target in the future for treating different kinds of diseases including the CVD. In addition to that, extensive search campaigns should be 
supported by the pharmaceutical industry to find new inhibitors against GSK-3 $\beta$.

\section{PI3K}

PI3K has been widely investigated and validated as an anticancer target; recently, new studies are focusing on class IA isoform of PI3K as a validated target for treating heart diseases [103]. Activation of PI3K (IA) is being investigated as a new approach for the treatment of heart failure [103-105].

\section{PI3K natural activators}

Resveratrol (3,5,4'-trihydroxy-trans-stilbene) (Figure 2) is a natural antioxidant that derived from the skin of grapes and berries [106]. A study published in 2015 by Chong et al. investigated the therapeutic effect of resveratrol in arterial fibrillation prevention and tested the hypothesis that the arterial fibrillation suppression mechanism works along the PI3K/AKT/eNOS pathway [106] [107]. Finally, this study set a conclusion that resveratrol regulates ionic channels and attenuates fibrosis through activation of the PI3K/AKT/eNOS signaling pathway [106]. However, no further investigation was done by this group to assess the activity of resveratrol as PI3K natural activators.

The cardiac glycoside ouabain (compound B) was also investigated as a PI3K-IA activator by Duan et al. [103]. Ouabain is already known to protect the heart muscle against ischemia-reperfusion injury, which is usually manifested clinically as acute MI [103]. Duan et al. used a pharmacological approach to study the mechanism by which ouabain works as a cardioprotector and was able to conclud that PI3KIA is actually involved in ouabain activity, but further studies are still needed to reveal the exact mechanism by which ouabain activates PI3K-IA [103].

\section{PI3K synthetic activators}

No synthetic activators of PI3K-IA are available in the literature. We recognized that all designed ligands for PI3K are inhibitors and are intended to inhibit the p $110 \alpha$ isoform of PI3K which is genetically linked to the occurrence of cancer but not to heart diseases [108].

\section{FAK}

FAK is a tyrosine kinase that facilitates cytoskeletal remodeling through the localization and activation of GTPase-activating proteins (GAPs). Activated FAK enhances the activation of diverse signaling pathways important in the regulation of cell migration [109]. In addition to its role in cell-to-extracellular matrix connection, it plays a significant role in cell proliferation, migration, adhesion and survival in a wide range of cell types. FAK has recently received attention as a poten- tial mediator of fibrosis in several cell types such as arterial and cardiac fibrosis processes. However, longterm effects on cardiac function and adverse cardiac remodeling are not clearly investigated [109]. A series of F-18 labeled 5-bromo-N2-(4-(2-fluoro-pegylated)3,5-dimethoxyphenyl)-N4-(4-ethoxyphenyl)pyrimidine-2,4-diamine derivatives was prepared and evaluated against FAK [110], but no further inhibitors were found against this target.

\section{G-protein-coupled receptor kinases}

G-protein-coupled receptors represent one of the largest families of membrane receptors that are responsible for regulating various biological processes. G-proteincoupled receptors are associated with heterotrimeric G-proteins and intracellular signaling pathways. G-protein-coupled receptor kinases (GRKs), along with $\beta$-arrestins, often desensitize receptor signal transduction, but the role of GRKs in cardiovascular pathophysiology is still not clear. Changes in GRK expression have been featured in many cardiovascular pathologies, including heart failure, MI, hypertension and cardiac hypertrophy. GRKs are now intensively studied as potential diagnostic or therapeutic targets.

\section{Conclusion}

The history of protein kinase research is massively rich with many biological discoveries in the field of CVD, and significant progress has been happening in this field since the discovery of Staurosporine in 1986. Various kinase inhibitor scaffolds have been synthesized and many natural products have been explored to treat CVDs, yet none has found its way to the market as a cardiovascular disease treatment; thus, more scientific efforts are needed in this regard. The future road to find new kinase drug to treat CVD is still full of obstacles, but we hope that the near future will carry to us good news

\section{Future perspective}

We really emphasize the importance of research efforts with an aim of finding specific and selective kinase inhibitors for treating CVDs by investing both the academic and scientific funding organizations' efforts simultaneously in the preclinical and clinical stages of drug development.

Nevertheless, the future road to a new kinase targeting cardiovascular drug is still full of obstacles because of the high degree of conservation in the protein amino acid sequence among different kinases. As such, the implementation of computational new methods in early stages of drug design may contribute significantly to developing specific and selective kinase inhibitors based on the differences in the binding pockets' amino acid sequences. 
Protein kinases are known to be ubiquitous, meaning that kinase inhibitors could give different therapeutic results in different tissues, and that is why specificity has been always an issue regarding the design of new therapies targeting protein kinases. Academic efforts should be set toward finding dissimilarities in the amino acid sequences between the kinases that are abundant in the heart and that are in other tissues. Furthermore, these dissimilarities should be exploited to find new specific active inhibitors of the heart kinases.

In future, ongoing design of new scaffolds against kinase enzymes is encouraged, but the collaboration between academia and pharmaceutical companies will help in moving the research results from the preclinical studies toward the different stages of clinical studies and finally to the market. As has seen, much preclinical research has been published in the literature, yet a few have expanded and continued. Pharmaceutical companies should adopt these small groups of researchers from all over the world and encourage them to continue their research. This especially applies to those researchers who work on natural products in distinctive natural areas; nature is replete with phytochemical agents that can serve as a lead compound to treat different diseases.

Also, academic research should be directed toward studying new localized drug-delivery systems designed for the purpose of targeting signaling pathways that are associated with cardiac function; specifically, localized drug-delivery systems are known to decrease the toxicity issues of drugs in general.
Finally, protein kinases are proven to be activated in heart disease and their inhibition has been shown to improve cardiac function, and so the efforts to find new kinase inhibitor active drug should continue due to the well-established role of kinases in the future.

\section{Acknowledgements}

The author would like to thank the deanship of scientific research in the Hashemite university for their support.

\section{Financial \& competing interests disclosure}

The authors have no relevant affiliations or financial involvement with any organization or entity with a financial interest in or financial conflict with the subject matter or materials discussed in the manuscript. This includes employment, consultancies, honoraria, stock ownership or options, expert testimony, grants or patents received or pending, or royalties.

No writing assistance was utilized in the production of this manuscript.

\section{Authors' contributions}

$\mathrm{R}$ Shahin reviewed the conception and design; R Shahin, FEl-Dahiyat and S Saffour reviewed acquisition of data; R Shahin, O Shaheen and M Habash made the analysis of data; R Shahin, $S$ Saffour and O Shaheen helped in drafting of manuscript; and $\mathrm{R}$ Shahin, O Shaheen and M Habash helped in critical revision.

\section{Open access}

This work is licensed under the Creative Commons Attribution 4.0 License. To view a copy of this license, visit http://creativecommons.org/licenses/by/4.0/

\section{Executive summary}

- Many kinase inhibitors have been synthesized in the last two decades, yet none has found its way to the market as a cardiovascular disease (CVD) treatment.

- Calmodulin-dependent protein kinase (CaMK)-II $\delta$ was one of the earliest kinase targets studied to treat CVDs. Many synthetic inhibitors for this enzyme were described in the literature. The most important are KN-62 and its derivatives, aryl-indolyl maleimide-based derivatives and Dainippon-25 $\left(\mathrm{IC}_{50}=12 \mathrm{nM}\right)$.

- CaMK-II are very promising, but still more scientific effort should be made to reveal the secrets of the allosteric binding site of CAMK-II and to design new inhibitors that can target mutually the hinge region of the ATP-binding pocket and the allosteric site of CAMK-II.

- Extensive studies have been done by several research groups to identify novel, potent and selective inhibitors against Rho kinase II (ROCK-II). Major advances in finding ROCK inhibitors were achieved; for example, compound Ar-13324 (structure not disclosed) developed by Aries ${ }^{\circledR}$ has reached Phase II in clinical studies to treat glaucoma but not CVDs.

- The future of protein kinase C (PKC)-targeting drugs should be more focused on monitoring the pharmacodynamics of new PKC modulators and revealing more information about the biology of different PKC isoforms.

- As for targeting p38 MAPK for CVD treatment, it is crystal clear that we are a few steps away from finding new kinase inhibitors to treat the inflammatory condition associated with atherosclerosis. Hopefully, in the near future we will see such a drug in the market.

- Extra studies and research are warranted to establish the role of glycogen synthase kinase $3 \beta$ as a useful therapeutic target in the future for treating CVD.

- The future road to find new kinase drug to treat CVD is still full of obstacles, but we hope that the near future will carry to us good news. 


\section{References}

Papers of special note have been highlighted as:

- of interest; $\bullet \bullet$ of considerable interest

1 Mozaffarian D, Benjamin EJ, Go AS et al. Heart Disease and Stroke Statistics-2015 Update. A report From the American Heart Association. Circulation 131(4), e29-e322 (2014).

2 Centers for Disease Control and Prevention. Heart disease facts. www.cdc.gov/heartdisease/facts.htm

3 Xu J, Murphy SL, Kochanek KD, Bastian BA. Deaths: final data for 2013. Natl Vital Stat. Rep. 64(2), 1-119 (2016).

4 Kumar R, Singh VP, Baker KM. Kinase inhibitors for cardiovascular disease. J. Mol. Cell Cardiol. 42(1), 1-11 (2007).

- The main article we used as a reference to start investigating the kinase inhibitors for treatment of cardiovascular disease.

5 Vagnozzi RJ, Hoffman NE, Elrod JW, Madesh M, Force T. Protein kinase signaling at the crossroads of myocyte life and death in ischemic heart disease. Drug Discov. Today Ther. Strateg. 9(4), e173-e182 (2012).

6 Roskoski R Jr. USFDA approved protein kinase inhibitors (2015). www.brimr.org/PKI/PKIs.htm

7 Kolluru GK, Majumder S, Chatterjee S. Rho-kinase as a therapeutic target in vascular diseases: striking nitric oxide signaling. Nitric Oxide 43, 45-54 (2014).

8 Kumar R, Singh VP, Baker KM. Kinase inhibitors for cardiovascular disease. J. Mol. Cell Cardiol. 42(1), 1-11 (2007).

9 Hidalgo CG, Chung CS, Saripalli C et al. The multifunctional $\mathrm{Ca}^{2+} / \mathrm{calmodulin}$-dependent protein kinase II delta (CaMKII $\delta$ ) phosphorylates cardiac titin's spring elements. J. Mol. Cell Cardiol. 54, 90-97 (2013).

10 Levy De, Wang DX, Lu Q et al. Aryl-indolyl maleimides as inhibitors of CaMKIIS. Part 1: SAR of the aryl region. Bioorg. Med. Chem. Lett. 18(7), 2390-2394 (2008).

11 Mavunkel B, Xu YJ, Goyal B et al. Pyrimidine-based inhibitors of CaMKIID. Bioorg. Med. Chem. Lett. 18(7), 2404-2408 (2008).

- The main articles we referred to through our search for $\mathrm{Ca}^{2+} /$ calmodulin-dependent protein kinase II inhibitors.

12 Liu Q, Molkentin JD. Protein kinase $\mathrm{C} \alpha$ as a heart failure therapeutic target. J. Mol. Cell. Cardiol. 51(4), 474-478 (2011).

13 Walker JW. Protein kinase C, troponin I and heart failure: overexpressed, hyperphosphorylated and underappreciated? J. Mol. Cell. Cardiol. 40 (4), 446-450 (2006).

14 Niizuma S, Inuzuka Y, Okuda J et al. Effect of persistent activation of phosphoinositide 3-kinase on heart. Life Sci. 90(15-16), 619-628 (2012).

15 Rose BA, Force T, Wang Y. Mitogen-activated protein kinase signaling in the heart: angels versus demons in a heartbreaking tale. Physiol. Rev. 90(4), 1507-1546 (2010).

16 Abraham ST, Benscoter HA, Schworer CM, Schworer CM, Singer HA. A role for $\mathrm{Ca}^{2+} / \mathrm{calmodulin}$-dependent protein kinase II in the mitogen-activated protein kinase signaling cascade of cultured rat aortic vascular smooth muscle cells. Circ. Res. 81(4), 575-584 (1997).
17 Hidalgo CG, Chung CS, Saripalli C et al. The multifunctional $\mathrm{Ca}\left({ }^{2+}\right) /$ calmodulin-dependent protein kinase II delta (CaMKIIdelta) phosphorylates cardiac titin's spring elements. J. Mol. Cell. Cardiol. 54, 90-97 (2013).

18 Picht E, Desantiago J, Huke S, Kaetzel MA, Dedman JR, Bers DM. CaMKII inhibition targeted to the sarcoplasmic reticulum inhibits frequency dependent acceleration of relaxation and $\mathrm{Ca}\left({ }^{2+}\right)$ current facilitation. J. Mol. Cell. Cardiol. 42(1), 196-205 (2007).

19 Swulius MT, Waxham MN. Ca(2+)/calmodulin-dependent protein kinases. Cell. Mol. Life Sci. 65(17), 2637-2657 (2008).

20 Barabutis N, Verin A, Catravas JD. Regulation of pulmonary endothelial barrier function by kinases. Am. J. Physiol. Lung Cell. Mol. Physiol. 311(5), L832 (2016).

21 Mayadevi M, Sherin DR, Keerthi VS, Rajasekharan KN, Omkumar RV. Curcumin is an inhibitor of calcium/ calmodulin dependent protein kinase II. Bioorg. Med. Chem. 20(20), 6040-6047 (2012).

22 Mayadevi M, Sherin DR, Keerthi VS, Rajasekharan KN, Omkumar RV. Curcumin is an inhibitor of calcium/ calmodulin dependent protein kinase II. Bioorg. Med. Chem. 20 (20), 6040-6047 (2012).

23 Tokumitsu H, Chijiwa T, Hagiwara M, Mizutani A, Terasawa M, Hidaka H. KN-62, 1-[N,O-bis (5isoquinolinesulfonyl)- $N$-methyl-L-tyrosyl]-4phenylpiperazine, a specific inhibitor of $\mathrm{Ca}^{2+} /$ calmodulindependent protein kinase II. J. Biol. Chem. 265(8), 4315-4320 (1990).

24 Davies SP, Reddy H, Caivano M, Cohen P. Specificity and mechanism of action of some commonly used protein kinase inhibitors. Biochem. J. 351, 95-105 (2000).

25 Yokokura H, Okada Y, Terada O, Hidaka H. HMN-709, a chlorobenzenesulfonamide derivative, is a new membranepermeable calmodulin antagonist. Jpn J. Pharmacol. 72(2), 127-135 (1996).

$26 \mathrm{Lu}$ Q, Chen Z, Perumattam J et al. Aryl-indolyl maleimides as inhibitors of CaMKII $\delta$. Part 3: importance of the indole orientation. Bioorg. Med. Chem. Lett. 18(7), 2399-2403 (2008).

27 Komiya M, Asano S, Koike N et al. Synthesis and structure based optimization of 2-(4-phenoxybenzoyl)-5hydroxyindole as a novel CaMKII inhibitor. Bioorg. Med. Chem. 20(23), 6840-6847 (2012).

28 Beauverger P, Gegis G, Biscarrat S, Duclos O, Mccort G. (2012). 5-Oxo-5,8-dihydropyridol [2,3-d] pyrimidine derivatives as CAMKII kinase inhibitors for treating cardiovascular disease. US patent, 0277220, 2012-11-01

29 Shahin R, Taha MO. Elaborate ligand-based modeling and subsequent synthetic exploration unveil new nanomolar $\mathrm{Ca}^{2+} /$ calmodulin-dependent protein kinase II inhibitory leads. Bioorg. Med. Chem. 20(1), 377-400 (2012).

- The main articles we referred to through our search for $\mathrm{Ca}^{2+} /$ calmodulin-dependent protein kinase II inhibitors.

30 Shahin R, Taha MO. Elaborate ligand-based modeling and subsequent synthetic exploration unveil new nanomolar $\mathrm{Ca}^{2+} / \mathrm{calmodulin}$-dependent protein kinase II inhibitory leads. (1464-3391 (Electronic)) (2012). 
31 Erickson JR. Mechanisms of CaMKII activation in the heart. Front. Pharmacol. 5, 59 (2014).

32 Knight ZA, Shokat KM. Features of selective kinase inhibitors. Chem. Biol. 12(6), 621-637 (2005). Wu P, Clausen MH, Nielsen TE. Allosteric small-molecule kinase inhibitors. Pharmacol. Ther. 156, 59-68 (2015).

Oh KS, Oh BK, Park CH et al. Cardiovascular effects of a novel selective Rho kinase inhibitor, 2-(1H-indazole-5-yl) amino-4-methoxy-6-piperazino triazine (DW1865). Eur. J. Pharmacol. 702(1-3), 218-226 (2013).

35 Noma K, Oyama N, Liao JK. Physiological role of ROCKs in the cardiovascular system. Am. J. Phsyiol. Cell Physiol. 290(3), C661-C668 (2006).

36 Schroter T, Minond D, Weiser A et al. Comparison of miniaturized time-resolved fluorescence resonance energy transfer and enzyme-coupled luciferase high-throughput screening assays to discover inhibitors of Rho-kinase II (ROCK-II). J. Biomol. Screen. 13(1), 17-28 (2008).

37 Feng Y, Yin Y, Weiser A et al. Discovery of substituted 4-(pyrazol-4-yl)-phenylbenzodioxane-2-carboxamides as potent and highly selective Rho kinase (ROCK-II) inhibitors. J. Med. Chem. 51(21), 6642-6645 (2008).

- Feng, the first author of this article, is one of the most important scientists who investigated Rho kinase enzyme for many years.

38 Ono-Saito N, Niki I, Hidaka H. H-series protein kinase inhibitors and potential clinical applications. Pharmacol. Ther. 82, 123 (1999).

39 Uehata M, Ishizaki T, Satoh H et al. Calcium sensitization of smooth muscle mediated by a rho-associated protein kinase in hypertension. Nature 389, 990 (1997).

- Described Fasudil, a unique rho kinase inhibitor, marketed in Japan to treat hypertension.

40 Feng Y, Lograsso PV, Defert O, Li R. Rho kinase (ROCK) inhibitors and their therapeutic potential. J. Med. Chem. 59(6), 2269-2300 (2016).

41 Cerebral Vasospasm. Seiler RW, Steiger HJ (Eds). SpringerVerlag Wien, Vienna, Austria (2001).

42 Mueller BK, Mack H, Teusch N. Rho kinase, a promising drug target for neurological disorders. Nat. Rev. Drug Discov. 4(5), 387-398 (2005).

43 Garnock-Jones KP. Ripasudil: first global approval. Drugs 74 , 2211 (2014).

44 Tanihara H, Inoue T, Yamamoto T et al. Phase II randomized clinical study of a rho kinase inhibitor, K-115, in primary open-angle glaucoma and ocular hypertension. $\mathrm{Am}$. J. Ophthalmol. 156, 731 (2013).

45 Tanihara H, Inoue T, Yamamoto T et al. Phase II clinical trials of a selective rho kinase inhibitor, K-115. JAMA Ophthalmol. 131, 1288 (2013).

46 Ikenoya M, Hidaka H, Hosoya T, Suzuki M, Yamamoto $\mathrm{N}$, Sasaki Y. Inhibition of rho-kinase-induced myristoylated alanine-rich C kinase substrate (MARCKS) phosphorylation in human neuronal cells by $\mathrm{H}-1152$, a novel and specific rho-kinase inhibitor. J. Neurochem. 81, 9 (2002).
47 Sasaki Y, Suzuki M, Hidaka H. The novel and specific rho-kinase inhibitor (S)-(+)-2-methyl-1-[(4-methyl-5isoquinoline) sulfonyl]-homopiperazine as a probing molecule for rho-kinase-involved pathway. Pharmacol. Ther. 93, 225 (2002).

48 Lavogina D, Kalind K, Bredihhina J et al. Conjugates of 5-isoquinolinesulfonylamides and oligo-D-arginine possess high affinity and selectivity towards Rho kinase (ROCK). Bioorg. Med. Chem. Lett. 22(10), 3425-3430 (2012).

49 Ishizaki T, Uehata M, Tamechika I et al. Pharmacological properties of Y-27632, a specific inhibitor of rho-associated kinases. Mol. Pharmacol. 57, 976 (2000).

50 Tokushige H, Waki M, Takayama Y, Tanihara H. Effects of Y-39983, a selective rho-associated protein kinase inhibitor, on blood flow in optic nerve head in rabbits and axonal regeneration of retinal ganglion cells in rats. Curr. Eye Res. 36, 964 (2011).

51 Feng Y, Cameron MD, Frackowiak B et al. Structureactivity relationships, and drug metabolism and pharmacokinetic properties for indazole piperazine and indazole piperidine inhibitors of ROCK-II. Bioorg. Med. Chem. Lett. 17, 2355 (2007).

52 Feng Y, Yin Y, Weiser A et al. Discovery of substituted 4-(pyrazol-4-yl)-phenylbenzodioxane-2-carboxamides as potent and highly selective rho kinase (ROCK-II) inhibitors. J. Med. Chem. 51, 6642 (2008).

53 Fang X, Yin Y, Wang B et al. Tetrahydroisoquinoline derivatives as potent and selective rho kinase inhibitors. J. Med. Chem. 53, 5727 (2010).

54 Mimi L, Quan Z, Wang C. Tricyclic pyrido-carboxamide derivatives as rock inhibitors WO 2015002926 A1 (2015).

55 Mishra RK, Alokam R, Singhal SM et al. Design of novel rho kinase inhibitors using energy based pharmacophore modeling, shape-based screening, in silico virtual screening, and biological evaluation. J. Chem. Inf. Model. 54(1), 2876-2886 (2014).

56 Oh KS, Oh BK, Park CH et al. Cardiovascular effects of a novel selective rho kinase inhibitor, 2-(1H-indazole-5-yl) amino-4-methoxy-6-piperazino triazine (DW1865). Eur. J. Pharmacol. 702, 218 (2013).

57 Shahin R, Alqtaishat S, Taha MO. Elaborate ligand-based modeling reveal new submicromolar Rho kinase inhibitors. J. Comput. Aided Mol. Des. 26(2), 249-266 (2012).

58 Feng Y, Lograsso P. Rho kinase inhibitors: a patent review (2012-2013). Expert Opin. Ther. Pat. 24, 295 (2014).

59 Feng Y, Lograsso PV, Defert O, Li R. Rho kinase (ROCK) inhibitors and their therapeutic potential. J. Med. Chem. 59(6), 2269-2300 (2016).

60 Churchill E, Budas G, Vallentin A, Koyanagi T, MochlyRosen D. PKC isozymes in chronic cardiac disease: possible therapeutic targets? Annu. Rev. Pharmacol. Toxicol. 48, 569-599 (2008).

61 Koide Y. Differential induction of protein kinase C isoforms at the cardiac hypertrophy stage and congestive heart failure stage in Dahl salt-sensitive rats. Hypertens. Res. 26, 421-426 (2003).

62 Liu Q, Molkentin JD. Protein kinase C $\alpha$ as a heart failure 
therapeutic target. J. Mol. Cell. Cardiol. 51, 474-478 (2011).

63 Mochly-Rosen D. Cardiotrophic effects of protein kinase C epsilon: analysis by in vivo modulation of $\mathrm{PKC}$ [epsiv] translocation. Circ. Res. 86, 1173-1179 (2000).

64 Ferreira JC. Pharmacological inhibition of $\beta I I P K C$ is cardioprotective in late-stage hypertrophy. J. Mol. Cell. Cardiol. 51, 980-987 (2011).

65 Ferreira JC, Boer BN, Grinberg M, Brum PC, Mochly-Rosen D. Protein quality control disruption by PKC $\beta I I$ in heart failure; rescue by the selective PKC $\beta$ II inhibitor, $\beta$ IIV5-3. PLoS ONE 7, e33175 (2012).

66 Ferreira JC, Brum PC, Mochly-Rosen D. $\beta I I P K C$ and $\varepsilon$ PKC isozymes as potential pharmacological targets in cardiac hypertrophy and heart failure. J. Mol. Cell. Cardiol. 51, 479-484 (2011).

67 Omura S, Iwai Y, Hirano A et al. A new alkaloid AM-2282 of Streptomyces origin. Taxonomy, fermentation, isolation and preliminary characterization. J. Antiobiot. (Tokyo) 30 (4), 275-282 (1977).

- Described Staurosporine and its analogs which are unique protein kinase $\mathrm{C}$ (PKC) natural inhibtor.

68 Radhika P, Kumar MMK, Nagasree KP. Protein kinase inhibitors from microorganisms. In: Studies in Natural Products Chemistry. Rahman AUr (Ed.). Elsevier, Amsterdam, The Netherlands 403-445 (2015).

69 Koshino H, Osada H, Isono K. A new inhibitor of protein kinase C, RK-1409 (7-oxostaurosporine). II. Fermentation, isolation, physico-chemical properties and structure. J. Antiobiot. (Tokyo) 45 (2), 195-198 (1992).

70 Osada H, Koshino H, Kudo T, Onose R, Isono K. A new inhibitor of protein kinase C, RK-1409 (7-oxostaurosporine). I. Taxonomy and biological activity. J. Antiobiot. (Tokyo) 45(2), 189-194 (1992).

71 Kobayashi E, Nakano H, Morimoto M, Tamaoki T. Calphostin C (UCN-1028C), a novel microbial compound, is a highly potent and specific inhibitor of protein kinase C. Biochem. Biophys. Res. Commun. 159(2), 548-553 (1989).

- Described Staurosporine and its analogs which are unique PKC natural inhibitor.

72 Wagner J, Von Matt P, Sedrani R et al. Discovery of 3-(1H-indol-3-yl)-4-[2-(4-methylpiperazin-1-yl) quinazolin4-yl] pyrrole-2,5-dione (AEB071), a potent and selective inhibitor of protein kinase C isotypes. J. Med. Chem. 52(20), 6193-6196 (2009).

73 Van Eis MJ, Evenou JP, Floersheim P et al. 2,6-Naphthyridines as potent and selective inhibitors of the novel protein kinase C isozymes. Bioorg. Med. Chem. Lett. 21(24), 7367-7372 (2011).

74 Li H, Hong Y, Nukui S et al. Identification of novel pyrrolopyrazoles as protein kinase $\mathrm{C}$ beta II inhibitors. Bioorg. Med. Chem. Lett. 21(1), 584-587 (2011).

75 Mochly-Rosen D, Das K, Grimes KV. Protein kinase C, an elusive therapeutic target? Nat. Rev. Drug Discov. 11(12), 937-957 (2012).

76 Packer M. Double-blind, placebo-controlled study of the efficacy of flosequinan in patients with chronic heart failure. Principal Investigators of the REFLECT Study. J. Am. Coll.
Cardiol. 22, 65-72 (1993).

77 Ruboxistaurin: LY 333531. Drugs R D 8(3), 193-199 (2007).

78 Poli A, Mongiorgi S, Cocco L, Follo MY. Protein kinase C involvement in cell cycle modulation. Biochem. Soc. Trans. 42(5), 1471 (2014).

79 Li H. Protein kinase C: novel isozyme-selective peptide inhibitors. Exp. Opin. Therap. Pat. 16(8), 1183-1187 (2006).

- Full review of PKC inhibitors.

80 Alam MA, Uddin SJ, Brown L. Mitogen-activated protein kinase and natural phenolic compounds in cardiovascular remodeling. In: Studies in Natural Products Chemistry. Rahman AUr (Ed.), Elsevier, 159-190 (2012).

81 Goetze S, Xi XP, Kawano Y et al. TNF-alpha-induced migration of vascular smooth muscle cells is MAPK dependent. Hypertension 33 (1 Pt 2), 183-189 (1999).

82 Willette RN, Eybye ME, Olzinski AR et al. Differential effects of p38 mitogen-activated protein kinase and cyclooxygenase 2 inhibitors in a model of cardiovascular disease. J. Pharmacol. Exp. Ther. 330 (3), 964 (2009).

83 Ren J, Zhang S, Kovacs A, Wang Y, Muslin AJ. Role of p38 alpha MAPK in cardiac apoptosis and remodeling after myocardial infarction. J. Mol. Cell. Cardiol. 38(4), 617-623 (2005).

84 Chen C, Yu R, Owuor ED, Kong AN. Activation of antioxidant-response element (ARE), mitogen-activated protein kinases (MAPKs) and caspases by major green tea polyphenol components during cell survival and death. Arch. Pharm. Res. 23(6), 605-612 (2000).

85 Cuenda A, Rouse J, Doza YN et al. SB 203580 is a specific inhibitor of a MAP kinase homologue which is stimulated by cellular stresses and interleukin-1. FEBS Lett. 364(2), 229-233 (1995).

86 Jackson JR, Bolognese B, Hillegass L et al. Pharmacological effects of SB 220025, a selective inhibitor of P38 mitogenactivated protein kinase, in angiogenesis and chronic inflammatory disease models. J. Pharmacol. Exp. Ther. 284(2), 687-692 (1998).

87 Wadsworth SA, Cavender DE, Beers SA et al. RWJ 67657, a potent, orally active inhibitor of $\mathrm{p} 38$ mitogen-activated protein kinase. J. Pharmacol. Exp. Ther. 291(2), 680-687 (1998).

88 Clinical Trials Database: NCT00996840 (2015). https://clinicaltrials.gov/ct2/show/NCT00996840

89 Laufer SA, Wagner GK, Kotschenreuther DA, Albrecht W. Novel substituted pyridinyl imidazoles as potent anticytokine agents with low activity against hepatic cytochrome $\mathrm{P} 450$ enzymes. J. Med. Chem. 46(15), 3230-3244 (2003).

90 Das J, Moquin RV, Pitt S, et al. Pyrazolo-pyrimidines: A novel heterocyclic scaffold for potent and selective p38 $\alpha$ inhibitors. Bioorg. Med. Chem. Lett. 18(8), 2652-2657 (2008).

91 Clinical Trials Database : NCT00570752 (2015). https://clinicaltrials.gov/ct2/show/NCT00570752

92 Clinical Trials Database: NCT00399906 (2015). https://clinicaltrials.gov/ct2/show/NCT00399906

93 Collis AJ, Foster ML, Halley F et al. RPR203494 a pyrimidine analogue of the $\mathrm{p} 38$ inhibitor RPR200765A with 
an improved in vitro potency. Bioorg. Med. Chem. Lett. 11(5), 693-696 (2001)

94 Haddad JJ. VX-745. Vertex Pharmaceuticals. Curr. Opin. Investig. Drugs 2(8), 1070-1076 (2001).

95 Sokol L, Cripe L, Kantarjian H et al. Randomized, doseescalation study of the p38 alpha MAPK inhibitor SCIO-469 in patients with myelodysplastic syndrome. Leukemia 27(4), 977-980 (2013).

96 Skurk C, Maatz H, Rocnik E, Bialik A, Force T, Walsh K. Glycogen-synthase kinase3beta/beta-catenin axis promotes angiogenesis through activation of vascular endothelial growth factor signaling in endothelial cells. Circ. Res. 96(3), 308-318 (2005).

97 Juhaszova M, Zorov DB, Yaniv Y, Nuss HB, Wang S, Sollott SJ. Role of glycogen synthase kinase-3beta in cardioprotection. Circ. Res. 104(11), 1240-1252 (2009).

98 Meijer L, Thunnissen AM, White AW et al. Inhibition of cyclin-dependent kinases, GSK-3beta and CK1 by hymenialdisine, a marine sponge constituent. Chem. Biol. 7(1), 51-63 (2000).

99 Leclerc S, Garnier M, Hoessel R et al. Indirubins inhibit glycogen synthase kinase-3 beta and CDK5/p25, two protein kinases involved in abnormal tau phosphorylation in Alzheimer's disease. A property common to most cyclindependent kinase inhibitors? J. Biol. Chem. 276(1), 251-260 (2001).

100 Leost M, Schultz C, Link A et al. Paullones are potent inhibitors of glycogen synthase kinase-3beta and cyclindependent kinase 5/p25. Eur. J. Biochem. 267(19), 5983-5994 (2000)

101 Mettey Y, Gompel M, Thomas V et al. Aloisines, a new family of CDK/GSK-3 inhibitors. SAR study, crystal structure in complex with CDK2, enzyme selectivity, and cellular effects. J. Med. Chem. 46(2), 22-236 (2003).

102 Zhang HC, White KB, Ye H et al. Macrocyclic bisindolylmaleimides as inhibitors of protein kinase $\mathrm{C}$ and glycogen synthase kinase-3. Bioorg Med. Chem. Lett. 13(18), 3049-3053 (2003).

103 Duan Q, Madan ND, Wu J et al. Role of phosphoinositide 3-kinase IA (PI3K-IA) activation in cardioprotection induced by ouabain preconditioning. J. Mol. Cell. Cardiol. $80,114-125$ (2015)

104 Pretorius L, Du XJ, Woodcock EA et al. Reduced phosphoinositide 3-kinase (p110 alpha) activation increases the susceptibility to atrial fibrillation. Am. J. Pathol. 175(3), 998-1009 (2001).

105 Mcmullen JR, Amirahmadi F, Woodcock EA et al. Protective effects of exercise and phosphoinositide 3-kinase(p110 alpha) signaling in dilated and hypertrophic cardiomyopathy. Proc. Natl Acad. Sci. USA 104(2), 612-617 (2007).

106 JasiŃski M, JasiŃska L, Ogrodowczyk M. Resveratrol in prostate diseases - a short review. Central European J. Urol. 66(2), 144-149 (2013).

107 Chong E, Chang SL, Hsiao YW, et al. Resveratrol, a red wine antioxidant, reduces atrial fibrillation susceptibility in the failing heart by PI3K/AKT/eNOS signaling pathway activation.. Heart Rhythm. 12(5), 1046-1056 (2015).

108 Liu P, Cheng H, Roberts TM, Zhao JJ. Targeting the phosphoinositide 3-kinase (PI3K) pathway in cancer. Nat. Rev. Drug Discov. 8(8), 627-644 (2009).

- Describes the role of PI3K-IA activation in cardioprotection.

109 Zhang J, Fan G, Zhao H et al. Targeted inhibition of focal adhesion kinase attenuates cardiac fibrosis and preserves heart function in adverse cardiac remodeling. Sci. Rep. 7 , 43146 (2017).

110 Fang Y, Wang D, Xu X et al. Synthesis, biological evaluation, and molecular dynamics (MD) simulation studies of three novel F-18 labeled and focal adhesion kinase (FAK) targeted 5-bromo pyrimidines as radiotracers for tumor. Eur. J. Med. Chem. 127, 493-508 (2017). 